\title{
The effects of intertrial and feature-target intervals on operant serial feature-positive discrimination learning
}

\author{
PETER C. HOLLAND \\ Duke University, Durham, North Carolina
}

\begin{abstract}
The effects of intertrial interval (ITI) and feature-target interval (FTI) on the nature of learning in discrete-trial operant serial feature-positive (feature $\rightarrow$ target $+/$ target - ) discrimination training were examined in two experiments with rats. Discrimination performance was acquired more rapidly with longer ITIs and shorter FTIs. In contrast, transfer to a separately trained target was greater with shorter ITIs regardless of FTI. Persistence of discrimination performance after feature extinction was greater with longer ITIs. Only the last of these performance measures showed evidence for invariance with constant I'TI/FTI ratios. The results are discussed in the context of theories of occasion setting.
\end{abstract}

Considerable evidence from my laboratory (see Holland, 1992, for a review) indicates that the temporal arrangement of elements within a compound stimulus can affect the way rats solve Pavlovian and operant featurepositive (FP) discriminations (XA+/A-). Apparently, when $X$ and $A$ are presented simultaneously on compound trials, solution of the discrimination primarily involves the establishment of excitatory associations between the feature $X$ and the unconditioned stimulus (US). But when $\mathrm{X}$ precedes $\mathrm{A}$ on compound trials, $\mathrm{X}$ also comes to modulate the action of an association formed between $A$ and the US, setting the occasion for the expression of behavior generated by the latter association. The distinction between these two solution strategies was supported by several kinds of data (Holland, 1992). For example, nonreinforced presentations of the $\mathrm{X}$ feature alone after simultaneous FP discrimination training severely reduced responding during the XA compound (as would be expected if that responding was the consequence of simple $\mathrm{X}$-US associations), but comparable $X$-alone presentations after serial FP training had negligible effects on X's ability to facilitate responding to A (Holland, 1989, 1991). Similarly, the range of transfer of $\mathrm{X}$ 's putative occasion-setting powers is typically more limited than that of X's simple excitation. Although X's excitation sums with that of any target cue, its occasionsetting powers often act only on cues that were explicitly trained as targets of occasion setters (e.g., Holland, 1989, 1992; Holland \& Haas, 1993) or, to a lesser extent, that were first trained and then extinguished (e.g., Holland, 1991; Rescorla, 1985).

This research was supported in part by grants from the National Science Foundation. I thank Marie Crock for technical assistance. The author's address is: Department of Psychology: Experimental, Box 90086, Duke University, Durham, NC 27708-0086 (e-mail: pch@) acpub.duke.edu)
Previous research investigated the importance of various detailed aspects of the within-compound temporal arrangement of stimuli on the acquisition of occasion setting. For example, Ross and Holland (1981) and Holland $(1986 \mathrm{a}, 1992)$ found that occasion setting was minimal at shorter feature-target intervals (FTIs) at supported considerable simple feature-US learning, but was substantial over a wide range of longer intervals, including intervals too long to support simple conditioning. Experiments that attempted to disentangle the normally confounded effects of feature-target and feature US intervals suggested that the FTI was the more critical determinant of occasion setting (Holland, 1992). Similarly, Holland (1986a) found that introducing a gap between the termination of the feature cue and the onset of the target facilitated the rats' acquisition of occasion setting to the feature. Both of these findings are consistent with a casual gestalt notion previously introduced (Holland, 1983) to describe conditions that favor the establishment of occasion setting. Holland (1983) suggested that occasion setting would be induced in FP discrimination learning whenever some perceptual discontinuity between the feature and other elements in the stream of events encouraged parsing those events as feature $\rightarrow$ [target-US] rather than, say, feature $\rightarrow$ US (as in simple conditioning) or [feature-target] $\rightarrow$ US (as in configural conditioning; e.g., Pearce, 1987). Insertion of a gap between feature and target and the use of lengthy FTIs would encourage the former parsing and discourage the latter two.

Within this perspective, temporal relations between trials might also be expected to play an important role in the acquisition of occasion setting. Although temporal separation of the feature from the [target-US] pair would encourage treating the latter pair as a unit, it is nevertheless essential that the feature be linked with that unit at some level. Thus, it is likely that the temporal isolation of feature $\rightarrow$ [target-US] sequences from other events in 
the conditioning session by using relatively lengthy intertrial intervals (ITIs) would also encourage the abstraction of the hierarchical relation underlying occasion setting. In contrast, the use of ITIs that are short relative to the FT I might make it difficult to group the feature with the [target-US] unit rather than with a preceding target-alone or US presentation. These notions are supported by informal comparisons of the acquisition rates found in operant serial FP discriminations in other published research from my laboratory. For example, in two separate experiments that used 10 -sec FTIs, acquisition to a common discrimination criterion took about five times as many trials when 1-min ITIs were used (Holland, 1991, Experiment 1) as when 4-min ITIs were used (Holland, 1995, Experiment 1).

Of course, according importance to the ITI in determining discrimination performance is not unique to this casual gestalt view. The ITI has been shown to be an important variable in determining simple conditioning: spaced practice is frequently found to be superior to massed practice (e.g., Gormezano \& Moore, 1969; G. A. Holland, 1953; Spence \& Norris, 1950). More interesting, several investigators (e.g., Gibbon, Baldock, Locurto, Gold, \& Terrace, 1977) have found the ITI to affect the within-trial CS-US interstimulus interval (ISI) function: ISIs that are too long for good conditioning at one ITI support substantial conditioning when conditioning trials are separated by longer ITIs. Indeed, Gibbon et al. (1977) found that acquisition of simple conditioning was a function of the ITI/ISI ratio regardless of the absolute values of those intervals. Similarly, accuracy in delayed matching-to-sample discrimination tasks, in which a sample cue informs subjects which of two choice cues presented after an intervening delay interval is the correct target of responding, is commonly found to be higher with longer ITIs (e.g., Grant, 1975). Furthermore, analogous to Gibbon et al.'s (1977) findings, Roberts and Kraemer (1982) found that the use of longer ITIs extended the delay intervals over which subjects could maintain information in delayed matching-to-sample procedures: discrimination accuracy was a simple function of the ratio of ITI and delay interval, regardless of the particular values of those intervals (at least within a moderate range of delay intervals).

The experiments reported here used a discrete-trial operant procedure to investigate the acquisition of serial FP discriminations as a function of both the intratrial FTI and the ITI. In Experiment 1, the FTI was $20 \mathrm{sec}$ and the ITIs were $1,2,4,8$, or $16 \mathrm{~min}$; in Experiment 2, the FTI was $10 \mathrm{sec}$ and the ITIs were $0.5,1,2,4$, or $8 \mathrm{~min}$. Thus, as in Gibbon et al.'s (1977) and Roberts and Kraemer's (1982) studies, performance at equivalent ITI/FT ratios with different constituent intervals could be compared.

Several effects of these temporal variations might be anticipated. First, existing data (Holland 1991, 1995) suggest that with both FTIs the use of longer ITIs should facilitate the acquisition of the serial FP discriminations. The casual gestalt notion implies enhancement of occasion setting, and previous data suggest that simple con- ditioning to the feature should be enhanced as well; thus, both solution strategies might be facilitated by the use of longer ITIs. Second, previous data from experiments with 8-min ITIs (Holland, 1986a, 1992) indicate that, asymptotically, simple conditioning should be greater with the 10-sec FTI than with the 20-sec FTI, but the levels of occasion setting would probably not differ appreciably across those two FTIs. Third, to the extent that the acquisition of simple conditioning and/or occasion setting are affected by the ITI/FTI ratio rather than the absolute values of either interval, performance of groups in Experiments 1 and 2 with equivalent ITI/ISI ratios would be similar, despite their differences in FTI and ITI.

In an attempt to distinguish between interval effects on simple conditioning and those on occasion setting, these experiments also examined discriminative performance after repeated nonreinforced presentation of the feature cue. On the basis of our previous claims (Holland, 1992, noted above), this manipulation would be expected to extinguish simple conditioned responding, leaving occasion setting as the primary determinant of performance in postextinction testing.

Both experiments also examined the effects of these interval variations on transfer of conditioned responding to compounds in which the original target cue was replaced by a separately trained and extinguished stimulus. Holland (1986b) noted effects of temporal variations within serial compounds on the amount of transfer in serial FP discriminations; the present experiments sought to extend those observations. Because typically I have found only small amounts of transfer of occasion setting to separately trained and extinguished target cues (e.g., Holland, 1992, noted above), one possibility to be entertained is that variations in transfer responding might mirror variations in the level of simple conditioning to the feature cue.

Finally, these experiments considered whether these manipulations of temporal variables affected learning or exerted their influence primarily at the time of performance. To that end, after separate groups of rats were trained with different ITI values, they were tested on common ITIs.

\section{EXPERIMENT 1}

In Experiment 1, five groups of rats first received serial conditioning, in which leverpressing during the auditory element of a light-trace-auditory serial compound was reinforced. Each group received these trials at a different average ITI: $1,2,4,8$, or 16 min. Next, all subjects were trained to discriminate between these serial compound trials, on which leverpressing was reinforced, and presentations of the auditory target cue alone, during which responding was not reinforced. Then all rats received additional discrimination training during which responding during another auditory cue was first reinforced and then nonreinforced.

Next, responding controlled by the two auditory target cues alone, the visual feature alone, and the serial com- 
pounds of the visual feature and each of the two auditory targets was examined in three test sessions to compare the breadth of transfer of the visual feature's stimulus control to the separately trained and extinguished target. To determine whether differences in the performance of the five groups were the result of different learning at the various training ITIs or simply the effect of those ITIs on the expression or performance of learning, separate transfer tests were conducted using the original training ITIs, the 1-min ITI in all groups, and the 8-min ITI in all groups.

After these tests, all subjects were given nonreinforced presentations of the visual feature alone and a final transfer test, using the original ITIs, was administered. Because the nonreinforced feature presentations would be expected to extinguish the feature's simple conditioning but leave its occasion-setting powers relatively unaffected, this final test was viewed as an index of occasion setting less confounded by simple conditioning.

\section{Method}

Subjects and Apparatus. The subjects were 20 male and 20 female albino rats, bred from Charles River (Raleigh, NC) stock in a Duke University facility. At the beginning of the experiment, they were experimentally naive and about 270 days old. The rats were maintained at $80 \%$ of their ad -lib body weights throughout the experiment by restricting their access to food. Water was available at all times in their individual home cages.

There were eight identical experimental chambers, each $22.9 \times$ $20.3 \times 20.3 \mathrm{~cm}$. The front and back walls of each chamber were aluminum; the side walls and top were clear acrylic. A food cup was recessed behind a $5 \times 5 \mathrm{~cm}$ opening in the front wall; the bottom of the opening was $2 \mathrm{~cm}$ from the floor, and its center was $2 \mathrm{~cm}$ to the right of the center of the front wall. A $6-\mathrm{W}$ jewelled lamp ("panel light") was centered on the front wall $4 \mathrm{~cm}$ above the top of the food-cup opening. Except when the panel light was illuminated as a signal, the chambers were dark. A $2 \times 2 \mathrm{~cm}$ lever was mounted $3 \mathrm{~cm}$ above the floor, $4 \mathrm{~cm}$ to the left of the food opening. During the first four sessions of leverpress training, the lever was enlarged by clipping a $3.3 \times 1.5 \mathrm{~cm}$ metal paper clamp over it. The floor of the chamber was composed of $0.48-\mathrm{cm}$ stainless steel rods spaced $1.9 \mathrm{~cm}$ apart.

Each of the chambers was enclosed in a sound-attenuating shell. Two speakers for delivering the auditory CSs were mounted on one wall of each shell, level with the top of the chamber and $2 \mathrm{~cm}$ in front of and $10 \mathrm{~cm}$ to the left of the front wall of the chamber. Two stimuli, a $72-\mathrm{dB}(\mathrm{A})$ square-wave $1500-\mathrm{Hz}$ tone and a $68-\mathrm{dB}, 8-\mathrm{Hz}$ clicker, were presented through one speaker, and a 72-dB white noise was presented through the other speaker. Finally, each shell was enclosed in another sound-attenuating box. Constant background noise $(62.5 \mathrm{~dB})$ was provided by a ventilating fan on each box:

Procedure. The rats were first trained to drink from the food cup and to press the lever. Each rat received one l-h session in which $0.3 \mathrm{ml}$ of $0.2 \mathrm{M}$ sucrose were delivered on a variable-time (VT) 2-min schedule during the first $40 \mathrm{~min}$ and each leverpress was reinforced with a similar sucrose delivery. Then the rats received three additional sessions in which each leverpress was reinforced but no response-independent sucrose was delivered. Each of these sessions was terminated for each rat as soon as it made 50 presses.

Next, all rats were trained to respond during an auditory (clicker) cue but not during the ITI in three 60 -min sessions. In each of these sessions, there were 60 presentations of the clicker, during which each leverpress produced sucrose delivery. The duration of each clicker presentation was 30,15 , and $5 \mathrm{sec}$ in the first, second, and third sessions, respectively.
Four male and 4 female rats were then randomly assigned to each of five groups and given preliminary training with the reinforced compound cues to be used in subsequent discrimination training. In each of the three sessions of preliminary training, the rats in all groups received $16 \mathrm{X} \rightarrow \mathrm{A}+$ presentations, in which a $5-\mathrm{sec}$ illumination of the panel-light feature $(X)$ was followed, after a 15 -sec empty interval, by a 5 -sec auditory target cue (A), during which each leverpress was reinforced. For half of the subjects in each group, A was the noise; for the other half, it was the $1500-\mathrm{Hz}$ tone.

For all groups, the FTI was $20 \mathrm{sec}$. The groups differed in their average ITIs, which were $1 \mathrm{~min}$ in Group $1-20,2 \mathrm{~min}$ in Group 2 $20,4 \mathrm{~min}$ in Group 4-20,8 $\mathrm{min}$ in Group 8-20, and $16 \mathrm{~min}$ in Group 16-20. In each group, the ITIs ranged from one-half to twice the mean ITI, rectangularly distributed. Session durations ranged from $16 \mathrm{~min}$ in Group 1-20 to $256 \mathrm{~min}$ in Group 16-20.

Next, the rats received discrimination training. In each session, the rats in each group received eight of the reinforced serial compound trials described above randomly intermixed with eight 5 -sec presentations of $\mathrm{A}$ alone, during which responding was not reinforced. The ITIs were the same as in the previous phase. The rats in the various groups were given different numbers of discrimination training sessions in an attempt to equalize performance levels before proceeding to the next phase of the experiment. The rats in Groups 4-20 and 8-20 received 14 discrimination training sessions, the rats in Group 16-20 received 18 sessions, the rats in Group 2-20 received 27 sessions, and the rats in Group 1-20 received 50 sessions.

Then the rats received initial training of the cue to be used as the transfer target, $B$. In each of two sessions, each rat received 16 presentations of the 5-sec B cue (either the tone or noise, whichever had not served as A), during which each leverpress was reinforced. In the first of these sessions, sucrose was delivered at the termination of each B presentation, independent of responding (this procedure frequently encourages initial contacting of the lever, which permits exposure to the instrumental contingency). Next, discrimination training was reinstated for eight sessions, in which four $\mathrm{X} \rightarrow \mathrm{A}+$ trials and four $\mathrm{A}-$ trials were intermixed with eight $\mathrm{B}$ trials. In the first four of these sessions, responding during $B$ was reinforced; during the last four sessions, responding during $\mathrm{B}$ was not reinforced.

The rats then received Test 1 , which examined X's ability to modulate responding to its original target $(A)$ and to the trainedand-extinguished transfer target $(B)$, maintaining the same mean ITls used in training. In each of the two sessions of Test 1 , there were three of each of five types of trials: the original $\mathrm{X} \rightarrow \mathrm{A}$ compound, the transfer $X \rightarrow B$ compound, the $X$ feature alone, and each of the two targets, $A$ and $B$, alone. To avoid confounding differences in ITI with trial type in these test sessions, the ITIs were fixed at the mean value in each group. Sucrose was unavailable during these sessions.

After a single retraining session with eight $\mathrm{X} \rightarrow \mathrm{A}+$ and eight $A$ - trials (with the original ITIs), the rats received two additional transfer-test sessions, which assessed performance of the various groups with common ITIs. These sessions were identical to Test 1 , except that for all groups the ITIs were $1 \mathrm{~min}$ in one test (Test 2) and $8 \mathrm{~min}$ in the other (Test 3 ). Half of the rats in each group were tested first with 1-min ITIs, and half were tested first with 8-min ITIs.

After three additional retraining sessions identical to the one given after Test 1 , the rats all received training designed to extinguish simple conditioning to the $\mathrm{X}$ feature. In each of two sessions, there were 16 presentations of the panel light with no sucrose available. The original ITIs were used in each group. Finally, X's remaining powers were examined in Test 4 , which was identical to Test 1 .

Data analysis. We recorded the rate of leverpressing, the percentage of trials on which at least one response occurred, and the 
latency of the first response during each 5-sec interval of conditioned stimulus (CS) presentations, empty trace intervals, and the 5 -sec pre-CS interval. However, response rates did not provide an appropriate measure of performance on reinforced trials: response rates were artificially suppressed on those trials because the rats did not press for several seconds after sucrose was delivered. Neither the latency nor the percentage of trials with a response measure was affected in this manner. Those two measures were closely related throughout the experiment, and led to identical conclusions. Because the latency measure was less affected by ceiling effects and seemed especially appropriate for studying the effects of temporal manipulations, I selected it as the primary measure in the present experiments. All three measures were analyzed, however, and any discrepancies in the conclusions derived from them are noted in the Results section below. A simple index of discrimination performance was calculated by subtracting the latency of responding to the target on compound trials from that on targetalone trials. Acquisition of the discrimination was also evaluated by examining the number of reinforced compound trials to reach an arbitrarily selected criterion of a discrimination difference score of $1.0 \mathrm{sec}$ over a two-session block of discrimination training.

Untransformed latencies were subjected to analyses of variance (ANOVAs). Between-group effects of ITI were assessed by analyses of orthagonal polynomial trends. The criterion of statistical significance adopted was $p<.05$.

\section{Results}

Except for the first few conditioning sessions, the rats seldom pressed during pre-CS intervals (fewer than $5 \%$ of those intervals). I do not discuss pre-CS responding further.

Conditioning. There were no differences in acquisition among the groups in the preliminary serial compound conditioning phase. Figure 1 shows the change in the latency of responding to the target cue on serial compound trials during that phase. A groups $\times$ sessions ANOVA showed an effect of sessions $[F(2,70)=41.39]$, but the effects of groups $[F(4,35)=1.20]$, linear and all higher order trends $[F \mathrm{~s}(1,35) \leq 2.64]$, and the groups $\times$ sessions interaction $[F(8,70)=1.49]$ were all insignificant.

Discrimination training. Figure 2 shows the acquisition of the FP discrimination in Experiment 1. Rats trained with longer ITIs acquired the discrimination more rapidly than those trained with shorter ITIs, primarily because the rats trained with longer ITIs more readily learned to withhold responding on the nonreinforced target-alone trials. Separate groups $\times$ sessions ANOVAs were performed for discrimination-difference scores, for latencies to respond on reinforced compound trials, and for latencies to respond on nonreinforced target-alone trials. Separate analyses were performed for Sessions 1-14 (which all five groups received) and for Sessions $15-28$ (which only Groups $1-20$ and 2-10 received). In addition, a one-way ANOVA was performed for the number of reinforced compound trials received before reaching the 1.0 -sec discrimination differencescore criterion.

The top panel of Figure 2 shows the discrimination difference scores. Over the first 14 sessions, the effects of groups $[F(4,35)=18.78]$, sessions $[F(13,455)=25.86]$, and the groups $\times$ sessions interaction $[F(52,455)=$

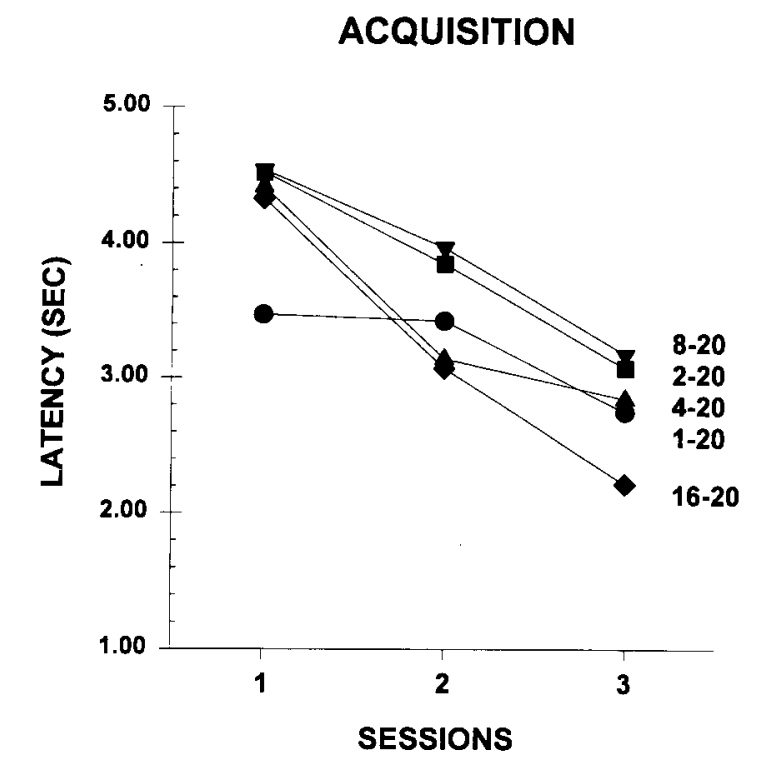

Figure 1. Mean latency to the first response to the target cue in the preliminary conditioning phase of Experiment 1. The group designations indicate first the intertrial interval in minutes and then the feature-target interval in seconds.

3.15] were all reliable. Discrimination performance was better in groups that were trained with longer ITIs: the linear trend across the groups was reliable $[F(1,35)=$ $64.97]$. The quadratic trend was also reliable $[F(1,35)=$ $8.87]$, but no higher order trends were significant. Newman-Keuls comparisons showed the performance of Group 1-20 to be reliably poorer than that of any other group and the performance of Group 2-20 to be significantly poorer than that of Groups 4-20, 8-20, and 16-20, whose performance did not differ reliably among themselves. Group 1-20 continued to show poorer performance than Group 2-20 over Sessions $15-28[F(1,14)=$ $10.01]$.

The number of trials to reach the discrimination criterion of a 1 -sec difference in response latency showed a similar pattern: the linear trend across groups was reliable $[F(1,35)=74.21]$ but the residual was not. NewmanKeuls comparisons showed Group 1-20's performance (67 trials) to be reliably poorer than that of any other group, Group 2-20's performance (34 trials) to be poorer than that of Groups 4-20 (18 trials), 8-20 (13 trials), and 16-20 (9 trials), and Group 4-20's performance to be poorer than that of Group 16-20. Trials-to-criterion scores for Experiments 1 and 2 are shown in Figure 15.

The center panel of Figure 2 shows the latency to respond to the target on reinforced compound trials over the course of acquisition. As in the preliminary conditioning phase, the latency to respond on reinforced trials was unaffected by ITI. Over the first 14 sessions, only the effect of sessions was significant $[F(13,455)=$ 14.73]. Neither trend analyses nor Newman-Keuls tests showed any reliable differences among the groups. Fur- 


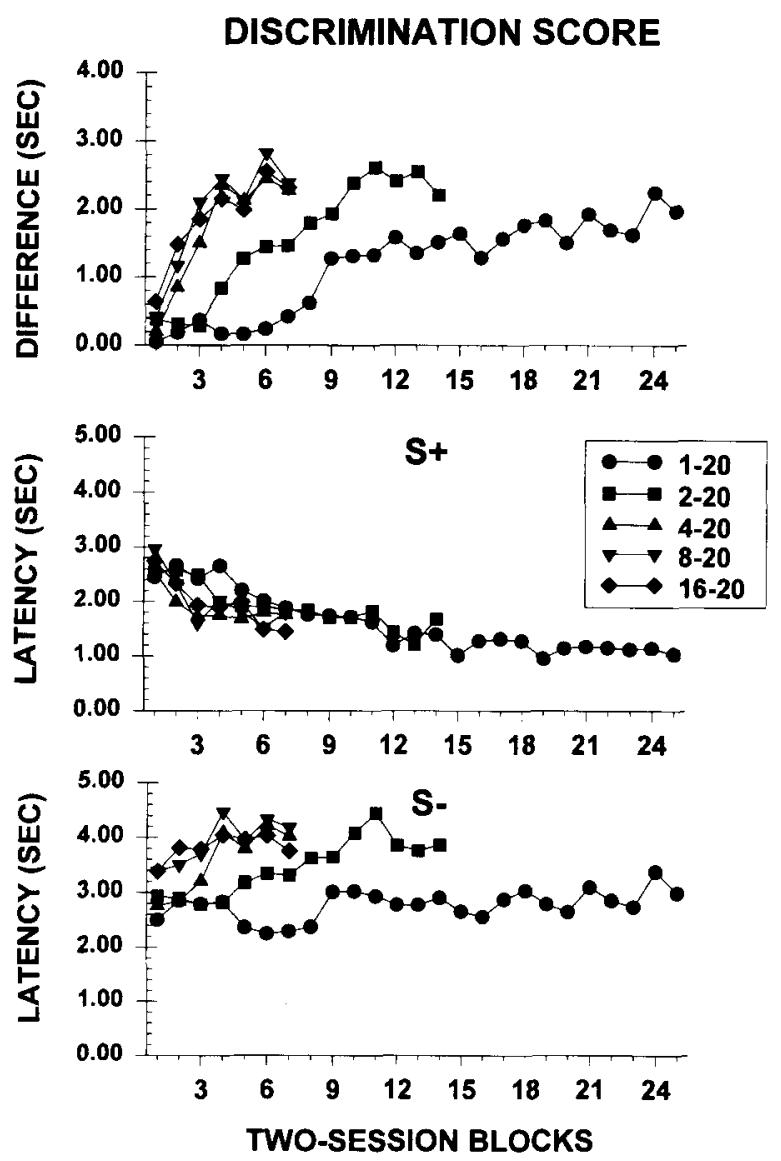

Figure 2. Performance during the first phase of serial feature positive discrimination training in Experiment 1 . The bottom panel portrays the mean latencies to respond to the target cue when it was presented alone ( $\mathrm{S}-$ ), the middle panel shows the mean latencies to respond to the target cues when they were preceded by the feature cue $(\mathrm{S}+)$, and the top panel shows a mean difference-score measure calculated by subtracting the latency to respond on $S+$ trials from that on $\mathrm{S}$ - trials. The group designations indicate first the intertrial interval in minutes and then the feature-target interval in seconds.

thermore, over Sessions 15-28, the latencies to respond to the reinforced compound did not differ between Groups $1-20$ and $2-20(F<1)$.

The bottom panel of Figure 2 shows the latency to respond on nonreinforced target-alone trials. This measure showed a pattern similar to that of the discrimination difference scores (top panel). Over the first 14 sessions, the effects of groups $[F(4,35)=14.08]$ and sessions $[F(13,455)=9.15]$ and the groups $\times$ sessions interaction $[F(52,455)=3.22]$ were all reliable. As with the discrimination difference scores, the linear trend of ITI across groups was reliable $[F(1,35)=51.43]$. Neither the quadratic $[F(1,35)=4.11, .05<p<.10]$ nor any higher order trend $(F \mathrm{~s}<1)$ was significant. NewmanKeuls tests showed reliably shorter response latencies (poorer performance) in Group 1-20 than in all other groups, and shorter latencies in Group 2-20 than in Groups 8-20 and 16-20. Over Sessions 15-28, the la- tency to respond on nonreinforced target-alone trials also differed reliably between Groups 1-20 and 2-20 $[F(1,14)=14.07]$

Next, all rats received another 10 sessions of discrimination training, during which training with another auditory cue, B, to be used later as a transfer test target stimulus, was intermixed. Leverpressing during $B$ was reinforced during Sessions $1-6$ of this phase and not reinforced during Sessions 7-10. Both the acquisition and extinction of leverpressing showed similar courses across the groups. On the final session in which leverpressing during $\mathrm{B}$ was reinforced, the mean latencies to respond to $B$ were $1.91,2.31,2.31,2.22$, and $1.51 \mathrm{sec}$ in Groups 1-20, 2-20, 4-20, 8-20, and 16-20, respectively. On the final session in which leverpressing during $B$ was not reinforced, those mean latencies were $3.24,2.94$, $3.83,4.17$, and $4.22 \mathrm{sec}$, respectively. There were no reliable differences in these latencies across the groups in either session $\left(F_{\mathrm{S}}<1.21\right)$. Thus, unlike responding to the A target of the serial FP discrimination, loss of responding to B was not affected by ITI.

Preextinction transfer tests. The results of the three preextinction transfer tests are shown in Figures 3-5. In each figure, response latencies on $\mathrm{X} \rightarrow \mathrm{A}$ original compound trials, $\mathrm{A}$-alone trials, $\mathrm{X} \rightarrow \mathrm{B}$ transfer compound trials, and B-alone trials are shown in the top panel, and discrimination difference scores (A minus $\mathrm{X} \rightarrow \mathrm{A}$ original discrimination, and $\mathrm{B}$ minus $\mathrm{X} \rightarrow \mathrm{B}$ transfer discrimination) are shown in the bottom panel. Responding on X-alone trials is not shown, because none of the groups showed responding on those trials, either during $\mathrm{X}$ or during any of the intervals after it, in any of the three preextinction transfer tests.

Figure 3 shows performance in Test 1 , in which the ITIs for each group were those used in training. Performance on the original discrimination was comparable across groups: none of the main effects of groups or of linear trends across groups for responding on $X \rightarrow A$ compound trials or for the A minus $\mathrm{X} \rightarrow \mathrm{A}$ discrimination difference scores was reliable $(p \mathrm{~s}>.10)$. However, the use of a common training criterion in Phase 1 was not completely successful in generating comparable performances among the groups: the main effect of groups and the linear trend across groups were reliable for responding on A-alone trials $[F(4,35)=3.39$ and $F(1,35)=$ 9.06 , respectively], with longer latencies (better performance), the longer the ITI.

Nevertheless, transfer of the $X$ feature's stimulus control to the separately trained $B$ target was greater, the shorter the ITI. The latency to respond on $\mathrm{X} \rightarrow \mathrm{B}$ transfer compound trials differed across the groups, as indicated by both a significant main effect of groups $[F(4,35)=4.01]$ and a reliable linear trend across groups $[F(1,35)=12.08]$ but no reliable effects for response latencies during the transfer target $(\mathrm{B})$ alone. Furthermore, the $\mathrm{B}$ minus $\mathrm{X} \rightarrow \mathrm{B}$ discrimination difference scores showed a reliable linear trend across groups as well $[F(1,35)=4.65]$, with transfer greatest at the shortest 


\section{TEST 1: ORIGINAL ITIS}
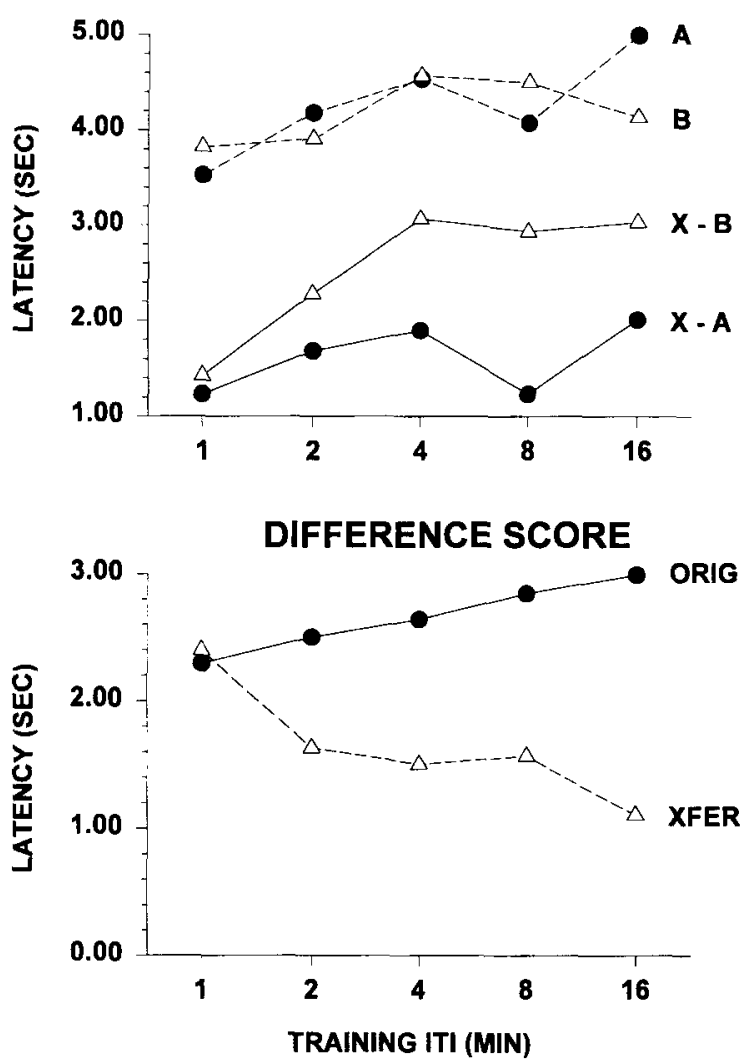

Figure 3. Performance during the first transfer test of Experiment 1 , in which the intertrial intervals (ITIs) were the mean of the original training intervals. The groups, indicated by their training ITIs, are arrayed along the abscissa. The top panel shows the mean latencies to the first response to the original (A) and transfer (B) targets when presented alone or when preceded by the $X$ feature. The bottom panel shows, for both the original, $X \rightarrow A+/ A-(O R I G)$, and transfer, $X \rightarrow B+/ B-$ (XFER), discriminations, the mean differences between the latencies to the first response to a target when it was presented alone and when it was preceded by the feature $(X)$.

ITIs. Finally, comparison of the difference scores for the original and transfer discriminations across the groups also showed a reliable linear trend $[F(1,35)=8.15]$, indicating that the between-group differences in transfer performance were not simply confounded with differences in performance on the original discrimination. Analyses of covariance of $\mathrm{X} \rightarrow \mathrm{B}$ scores with $\mathrm{X} \rightarrow \mathrm{A}, \mathrm{A}$, and/or $B$ as covariates all led to a similar conclusion.

Figure 4 shows performance during Test 2 , in which trials were presented with 1 -min ITIs in all groups. The major finding of this test was that, relative to Test 1, performance on the original discrimination was disrupted in groups that had been trained with longer ITIs. Although the latencies to respond on $\mathrm{A}-$ alone and $\mathrm{B}$-alone trials did not differ among the groups $(F \mathrm{~s}<2)$, response latencies on both the original $\mathrm{X} \rightarrow \mathrm{A}[F(1,35)=16.18]$ and the $X \rightarrow B$ transfer compound $[F(1,35)=7.61]$ were greater, the shorter the training ITIs. Similarly, both the original $[F(1,35)=6.54]$ and the transfer $[F(1,35)=$ 7.99] discrimination difference scores were greater, the shorter the ITIs received in training. Consequently, a comparison of the difference scores for the original and transfer discriminations showed no reliable differences $(F<1)$. These data contrast with those of Test 1 , in which only performance on the transfer discrimination was poorer in the groups trained with longer intervals.

Figure 5 shows performance during Test 3 , in which trials were presented with 8-min ITIs in all groups. Responding in this test was qualitatively similar to that in Test 1 . Response latencies on $\mathrm{X} \rightarrow \mathrm{A}, \mathrm{A}$, and $\mathrm{B}$ trials did not differ among the groups $\left(F_{\mathrm{S}}<2\right)$, but the latencies to respond on $\mathrm{X} \rightarrow \mathrm{B}$ transfer trials was greater, the shorter the training ITI $[F(1,35)=4.44]$. Furthermore, although neither the $\mathrm{A}$ minus $\mathrm{X} \rightarrow \mathrm{A}$ original discrimination difference scores nor the $\mathrm{B}$ minus $\mathrm{X} \rightarrow \mathrm{B}$ transfer discrimination difference scores showed a reliable linear trend across groups $[F(1,35) \leq 3.35]$, both the differences be-
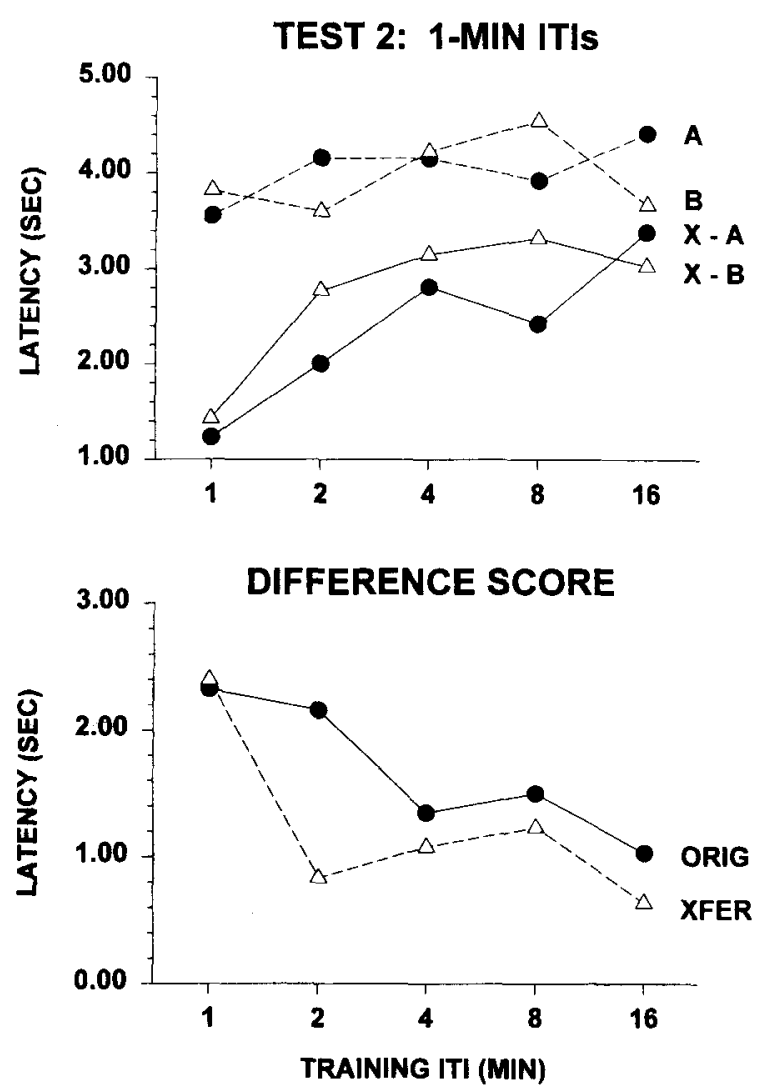

Figure 4. Performance during Transfer Test 2 of Experiment 1, in which the intertrial intervals (ITIs) were $1 \mathrm{~min}$ in all groups. The groups, indicated by their training ITIs, are arrayed along the abscissa. The top panel shows the mean latencies to the first response to the original (A) and transfer (B) targets presented alone or when preceded by the $X$ feature. The bottom panel shows, for both the origi$\mathrm{nal}, \mathbf{X} \rightarrow \mathbf{A}+/ \mathbf{A}-$ (ORIG), and transfer, $X \rightarrow B+/ B-(\mathbf{X F E R})$, discriminations, the mean differences between the latencies to the first response to a target when it was presented alone and when it was preceded by the feature $(X)$. 
TEST 3: 8-MIN ITIS
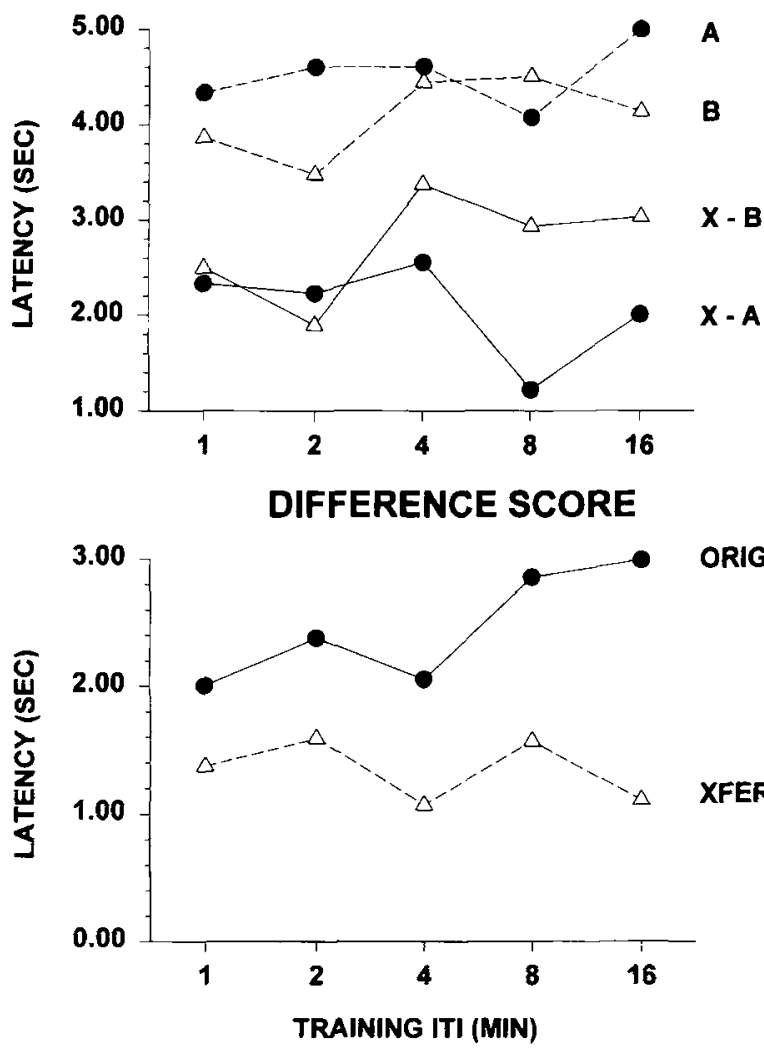

Figure 5. Performance during the transfer test of Experiment 1 in which the intertrial intervals (ITIs) were $8 \mathrm{~min}$ in all groups. The groups, indicated by their training ITls, are arrayed along the abscissa. The top panel shows the mean latencies to the first response to the original (A) and transfer (B) targets when presented alone or when preceded by the $X$ feature. The bottom panel shows, for both the original, $X \rightarrow A+/ A-$ (ORIG), and transfer, $X \rightarrow B+/ B-$ (XFER), discriminations, the mean differences between the latencies to the first response to a target when it was presented alone and when it was preceded by the feature $(X)$.

tween those difference scores $[F(1,35)=3.87]$ and the difference between responding on $\mathrm{X} \rightarrow \mathrm{A}$ and $\mathrm{X} \rightarrow \mathrm{B}$ trials $[F(1,35)=9.97]$ exhibited such a trend. Thus, as in Test 1 , transfer in this test was greater, the shorter the ITI in training.

Postextinction transfer test. Because feature extinction typically reduces simple feature conditioning substantially, but leaves occasion setting intact, Test 4 was intended as a test of occasion setting under conditions of reduced feature conditioning. None of the groups showed responding during the pre-CS periods or on panel light-alone trials either during that light or during any of the intervals after it.

Figure 6 shows performance in Test 4. First, despite extinction of the $X$ feature prior to Test 4 , some performance of the original discrimination was maintained in all groups; individual contrasts of response latencies on $\mathrm{X} \rightarrow \mathrm{A}$ and $\mathrm{A}$-alone trials were reliable in all five groups $[F \mathrm{~s}(1,105) \geq 4.25]$. Second, responding during the orig- inal $\mathrm{X} \rightarrow \mathrm{A}$ compound occurred with shorter latencies, the longer the ITI $[F(1,35)=6.12]$, suggesting that $X$ feature extinction especially increased response latencies when short ITIs had been used in training. Third, there were no effects of group or trends across groups for response latencies during any other cue $(p \mathrm{~s} \geq 10)$. Fourth, transfer responding was not maintained reliably; individual contrasts of response latencies on $\mathrm{X} \rightarrow \mathrm{B}$ and $B$-alone trials failed to reach significance in any of the groups $[F \mathrm{~s}(1,105) \leq 3.85]$. Consequently, performance on the original discrimination was better, the longer the ITI $[F(1,35)=6.59]$, whereas there was no such trend for performance on the transfer discrimination $[F(1,35)=1.64]$. The difference between the original and transfer discrimination difference scores also increased as a function of ITI $[F(1,35)=7.06]$.

Figure 7 shows the difference between Test 4 (postextinction) and Test 1 (preextinction) in the latencies to respond to the original (A) and transfer (B) targets on compound trials. Latencies to respond on both $\mathrm{X} \rightarrow \mathrm{A}$ and $\mathrm{X} \rightarrow \mathrm{B}$ trials were little affected by the intervening
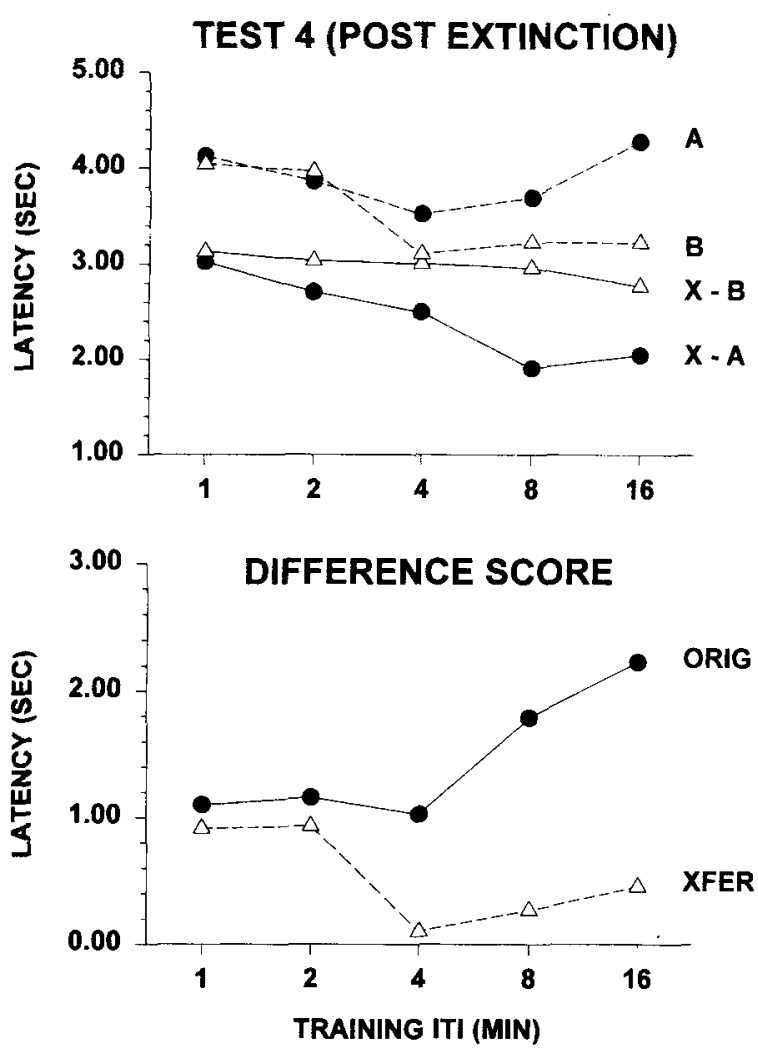

Figure 6. Performance during the fourth transfer test of Experiment 1 , which was identical to Transfer Test 1 but which occurred after repeated nonreinforced presentations of the $X$ feature in all groups. The groups, indicated by their training ITIs, are arrayed along the abscissa. The top panel shows the mean latencies to the first response to the original (A) and transfer (B) targets presented alone, or when preceded by the $X$ feature. The bottom panel shows, for both the original, $X \rightarrow A+/ A-(O R I G)$, and transfer, $X \rightarrow B+/ B-$ (XFER), discriminations, the mean differences between the latencies to the first response to a target when it was presented alone and when it was preceded by the feature $(X)$. 
treatment in groups trained with the longer ITIs, but substantially affected in the groups trained with shorter ITIs. Analysis of the Test 4 minus Test 1 difference scores showed a reliable linear trend across groups for both $\mathrm{X} \rightarrow \mathrm{A}[F(1,35)=6.96]$ and $\mathrm{X} \rightarrow \mathrm{B}[F(1,35)=$ $7.67]$ trials. Note that the lack of a change in $X \rightarrow B$ responding in the groups with longer ITIs reflects the very low level of such responding in both tests rather than the maintenance of transfer after extinction in those groups.

\section{Discussion}

Unlike Gibbon et al.'s (1977) experiments, there was no reliable effect of ITI on the acquisition of conditioning (as measured by reduced response latency) to the target cue within the serial compounds in this experiment, either in the initial, serial conditioning phase or within FP discrimination training. However, several aspects of this experiment are worth noting in this regard. First, acquisition of conditioning was very rapid in all groups, and thus initial acquisition may not have been adequately sensitive to reveal effects like those of Gibbon et al. Second, prior to the serial conditioning phase, the rats were trained to leverpress during another auditory cue, with identical ITIs in all groups, which may also have biased acquisition performance. Third, even the shortest ITI used ( $1 \mathrm{~min}$ ) was long relative to those used in many studies (although Gibbon et al., 1977, used intervais up to $16 \mathrm{~min}$ ), and thus we may have ignored the intervals that would have shown the greatest effect on performance. Finally, the ITls in our experiments were variable, across a broad range around the mean, whereas Gibbon et al.'s intervals were fixed; Roberts and Kraemer (1982) noted greater effects of ITI when those intervals were fixed.

Nevertheless, learning of the FP discrimination was substantially affected by ITI. First, acquisition of discrimination performance was more rapid the longer the ITI, reflecting more rapid loss of responding during non-

CHANGE IN RESPONSE TO COMPOUNDS

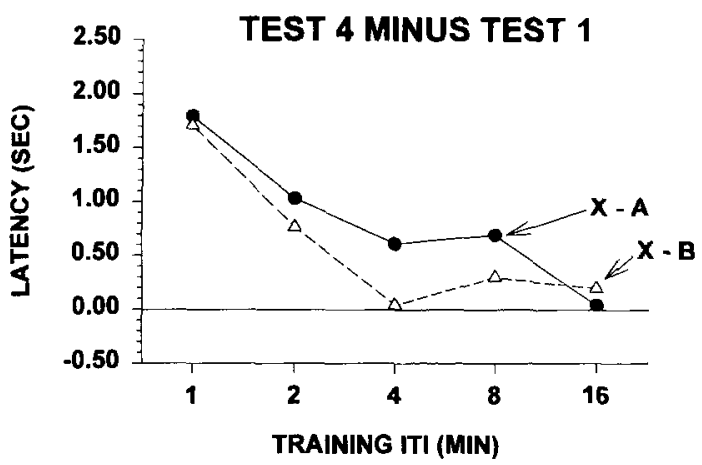

Figure 7. The mean differences between the latencies to respond to the original $(X \rightarrow A)$ or transfer $(X \rightarrow B)$ compounds in Transfer Test 1 and those in 'Transfer Test 4 (after extinction of the feature cue, $X$ ) in Experiment 1 . The groups, indicated by their training intertrial intervals (ITIs), are arrayed along the abscissa. reinforced target-alone trials. Thus, although acquisition of conditioning to $S+$ was apparently unaffected by ITI, loss of conditioning during $\mathrm{S}$ - was enhanced with longer ITIs. Second, the results of the transfer and postextinction tests indicate that variations in ITI also affected the character of the learning of the FP discriminations. Transfer to a separately trained and extinguished target cue was minimal with longer ITIs but nearly complete with shorter ITIs. Similarly, responding to the original compound was more resistant to feature extinction with longer ITIs than to that with shorter ITIs.

Both of the latter two findings are consistent with the claim that although the longer ITIs especially encouraged the use of an occasion-setting strategy, simple conditioning of the feature contributed more to discrimination performance with shorter ITIs. The observation that performance on the transfer discrimination (which might reflect mostly simple conditioning) was reduced proportionately more by feature extinction than was performance on the original discrimination (to which occasion setting would also contribute) further supports this account.

However, objections to this interpretation of both the transfer and extinction effects might be made. For example, it seems reasonable to suggest that the variations in the ITI affected the likelihood of transfer of occasion setting, rather than affecting the mix of occasion setting and simple conditioning. Cues trained with short ITls might simply be better targets of transfer than those trained at longer ITls. Supporting this possibility is the observation that, in the shorter ITl groups, some transfer responding did persist after feature extinction.

Concerning the extinction effects, it might be argued that because of the lack of a no-extinction control condition, the changes in responding between preextinction and postextinction tests cannot be attributed solely to the effects of the intervening nonreinforced feature presentations (rather than, say, the passage of time, the occurrence of other test sessions, or exposure to the experimental context). Similarly, rather than reflecting greater initial levels of simple conditioning, the extinction effects might reflect a greater effectiveness of short ITIs in producing extinction. However, the results of the discrimination training phases make that possibility unlikely; extinction of responding during the separately trained $\mathrm{B}$ cue was unaffected by ITI, and nonreinforced presentations of the original $A$ target increased response latencies more with longer ITIs than with shorter ITIs. All in all, systematic between-group differences in the amount of change in performance consistent with previous findings and present hypotheses about the effects of feature extinction on conditioning and occasion setting were, in fact, observed.

But perhaps the most telling objection to interpreting the results of the transfer and postextinction tests as indicating ITI-produced variations in the amounts of simple conditioning was that there was no evidence for responding on feature-alone trials in testing, either before 
or after feature extinction. Although it might be argued that simple conditioning was not revealed on featurealone trials because the rats were incapable of timing their responding to fall within the measurement interval in the absence of some marker cue, certainly it must be said that the most direct evidence for any simple conditioning to the feature was lacking. If simple conditioning was not involved, then the systematic variations in the acquisition, transfer, and extinction effects must instead be attributed to variations in the nature of occasion setting itself.

Whatever their origins, the effects of ITI were not attributable solely to performance factors, but involved effects on learning itself. Comparable patterns of data were observed when the rats were tested at their original training ITIs and when they were tested at a common 8 -min ITI. On the other hand, there were significant local performance effects as well. Performance of subjects trained with long (4-16 min) ITIs deteriorated when they were tested with 1-min ITIs. (Given that $1-$ min ITIs fell within the range of the distribution of ITIs in training in Group 2-20, it is perhaps not surprising that no decrement in performance of that group was seen when tested with 1-min ITIs.) Thus, short ITIs interfered with both the learning and expression of FP discrimination responding.

\section{EXPERIMENT 2}

Experiment 2 was identical to Experiment 1, except that the feature-target interval was $10 \mathrm{sec}$ rather than $20 \mathrm{sec}$, and the ITls used were $0.5,1,2,4$, and $8 \mathrm{~min}$. These values preserved Experiment 1's ITI/FTI ratios of $3,6,12,24$, and 48, despite the altered FTI.

\section{Method}

Subjects and Apparatus. The subjects were 20 male and 20 female albino rats, bred from Charles River (Raleigh, NC) stock in a Duke University facility. At the beginning of the experiment, they were experimentally naive and about 180 days old. The rats were maintained at $80 \%$ of their ad-lib body weights throughout the experiment by limiting their access to food. Water was available at all times in their individual home cages.

The apparatus was that used in Experiment 1.

Procedure. With the following three exceptions, the procedures of Experiment 2 were identical to those of Experiment 1: (1) The FTI was $10 \mathrm{sec}$ (with a 5 -sec empty interval between the feature and target cues) on compound trials throughout Experiment 2, rather than $20 \mathrm{sec}$ as in Experiment 1. (2) The ITIs used in the five groups were $30 \mathrm{sec}$ (Group 0.5-10), $1 \mathrm{~min}$ (Group 1-10), $2 \mathrm{~min}$ (Group 2-10), $4 \mathrm{~min}$ (Group 4-10), and $8 \mathrm{~min}$ (Group 8-10). (3) All groups in Experiment 2 received the same number of discrimination training sessions (12) prior to transfer-cue training.

\section{Results}

As in Experiment 1, the rats seldom pressed during pre-CS intervals (fewer than 5\% of those intervals); pre$\mathrm{CS}$ responding is not discussed further.

Conditioning. Figure 8 shows the change in the latency of responding to the target cue on serial compound trials during the preliminary conditioning phase of Experiment 2 . Acquisition was apparently more rapid in groups with intermediate ITIs. A groups $\times$ sessions ANOVA showed an effect of sessions $[F(2,70)=$ $113.12]$, and a reliable quadratic trend across groups $[F(1,35)=9.33]$. The linear trend across groups was not significant $(F<1)$. Individual Newman-Keuls comparisons showed latencies to be reliably longer in Group 0.5-10 than in Groups 4-10 and 2-10; no other differences were significant.

Discrimination training. Figure 9 shows the acquisition of the FP discrimination in Experiment 2. Rats trained with the shortest $(0.5-\mathrm{min})$ ITI showed the poorest acquisition of the discrimination; otherwise, there was little difference among the groups. Unlike in Experiment 1 , differences in discrimination performance reflected differences in performance on both reinforced and nonreinforced trials, as long as the performance of Group 0.5-10 was included in the analyses. Separate groups $\times$ sessions ANOVAs were performed for discrimination difference scores, for response latencies on reinforced compound trials, and for response latencies on nonreinforced target-alone trials, as was a one-way ANOVA for trials to reach the criterion of a $1.0-\mathrm{sec}$ difference in response latency between $\mathrm{S}+$ and $\mathrm{S}-$.

The top panel of Figure 9 shows the discrimination difference scores. The effects of groups $[F(4,35)=$ 9.36], sessions $[F(11,385)=48.81]$, and the groups $\times$ sessions interaction $[F(44,385)=1.93]$ were all reliable. Both the linear $[F(1,35)=22.07]$ and the quadratic $[F(1,35)=15.18]$ trends across groups were reliable. Newman-Keuls comparisons showed the performance of Group $0.5-10$ to be reliably poorer than that of any other

\section{ACQUISITION}

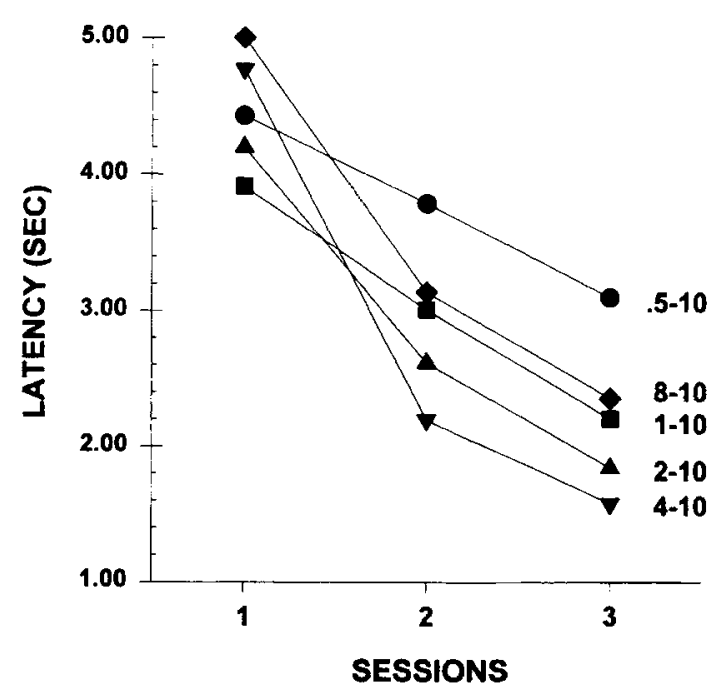

Figure 8. Mean latency to the first response to the target cue in the preliminary conditioning phase of Experiment 2. The group designations indicate first the intertrial interval in minutes and then the feature-target interval in seconds. 


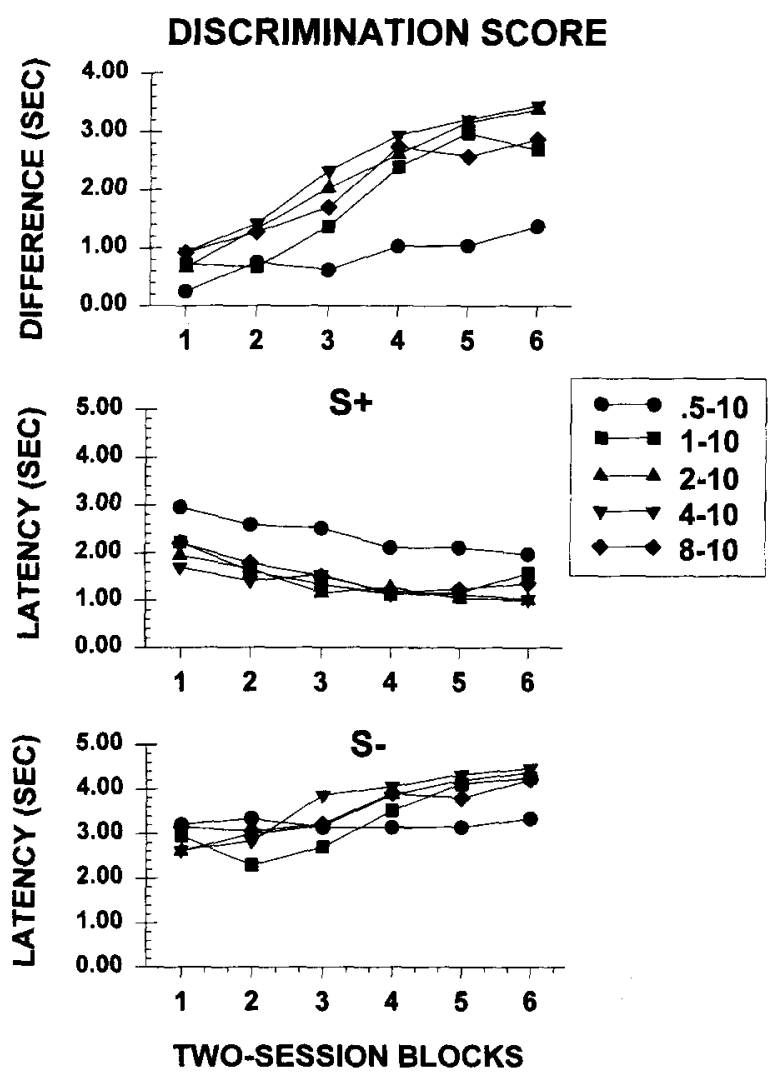

Figure 9. Performance during the first phase of serial featurepositive discrimination training in Experiment 2. The bottom panel portrays the mean latency to respond to the target cue when it was presented alone ( $\mathrm{S}-$ ), the middle panel shows the mean latency to respond to the target cues when they were preceded by the feature cue $(S+)$, and the top panel shows a mean difference score measure calculated by subtracting the latency to respond on $S+$ trials from that on $\mathbf{S}$ - trials. The group designations indicate first the intertrial interval in minutes and then the feature-target interval in seconds.

group; no other individual comparisons were reliable. A post hoc contrast of performance of the two intermediateinterval groups (2-10 and 4-10) with the remaining outlying groups ( $1-10$ and $8-10)$, suggested by the results of the test of quadratic trend, was also insignificant $[F(1,35)=1.62]$.

The analysis of trials to criterion showed a slightly more graded trend. Both linear and quadratic trends across groups were reliable $[F \mathrm{~s}(1,35) \geq 12.71]$, and Newman-Keuls comparisons showed the performance of Group 0.5-10 (35 trials) to be poorer than that of the other groups and the performance of Group 1-10 (19 trials) to be poorer than that of Groups 4-10 ( 9 trials) and 8-10 (10 trials). (Trials to criterion for Experiments 1 and 2 are shown in Figure 15.)

The center panel of Figure 9 shows the latency to respond to the target on reinforced compound trials over the course of acquisition. The effects of groups $[F(4,35)=$ $6.86]$ and sessions $[F(11,385)=15.46]$ were both reliable, but the groups $\times$ sessions interaction was not
$[F(44,385)=1.17]$. The differences among groups was attributable to longer latencies in Group 0.5-10; NewmanKeuls tests showed response latencies in that group to be reliably different from those in the remaining groups, which did not differ among themselves. No other contrasts were reliable.

The bottom panel of Figure 9 shows the latency to respond on nonreinforced target-alone trials. The effects of sessions $[F(11,385)=21.52]$ and the groups $\times$ sessions interaction $[F(45,385)=2.49]$ were both reliable, although the effect of group was not $[F(4,35)=1.52]$. As with discrimination difference scores, the linear trend of ITI across groups was also reliable $[F(1,35)=4.52]$ but the quadratic trend was not $(F<1)$. Newman-Keuls tests showed reliably shorter response latencies (poorer performance) in Group 0.5-10 than in all other groups and no other differences.

After the initial discrimination training, the rats received another 10 sessions of discrimination training that included intermixed training trials with another auditory cue, B, to be used later as a transfer-test target stimulus. Leverpressing during $B$ was reinforced during Sessions 1-5 of this phase and not reinforced during Sessions $6-10$. Both the acquisition and extinction of leverpressing showed similar courses across the groups. On the final session in which leverpressing during $B$ was reinforced, the mean latencies to respond were $1.73,1.50$, $1.66,1.48$, and $1.70 \mathrm{sec}$ in Groups $0.5-10,1-10,2-10,4-$ 10 , and $8-10$, respectively. In the final session in which leverpressing during $B$ was not reinforced, those mean latencies were $3.94,3.68,3.31,3.98$, and $3.74 \mathrm{sec}$, respectively. Between-group differences in responses latencies were not reliable for either session $\left(F_{\mathrm{S}}<1\right)$.

Preextinction transfer tests. The results of the three preextinction transfer tests are shown in Figures 10-12. As in Figures 3-5, latencies on $\mathrm{X} \rightarrow \mathrm{A}$ original compound trials, $\mathrm{A}$-alone trials, $\mathrm{X} \rightarrow \mathrm{B}$ transfer compound trials, and B-alone trials are shown in the top panels and discrimination difference scores are shown in the bottom panels. In addition, the top panels show response latencies on X-alone trials. Unlike in Experiment 1, some responding was observed on panel-light feature-alone trials in all groups. This difference is not surprising given the shorter feature-US interval in Experiment 2, which was expected to engender more simple feature conditioning. Although responding was occasionally observed during the panel-light feature itself, it was most frequent during the 5-sec empty trace interval when the target would have been delivered on compound trials. Consequently, the measure of responding on $\mathrm{X}$-alone trials reported here was the latency of the first response after the beginning of that interval (which was not explicitly signaled to the rat in any way). At least 7 of the 8 rats in each group showed shorter latencies to respond in these intervals than they did during the pre-CS intervals on those trials.

Figure 10 shows performance in Test 1 , in which the ITIs for each group were those used in training. As in Experiment 1 , the difference scores for the original 


\section{TEST 1: ORIGINAL ITIS}
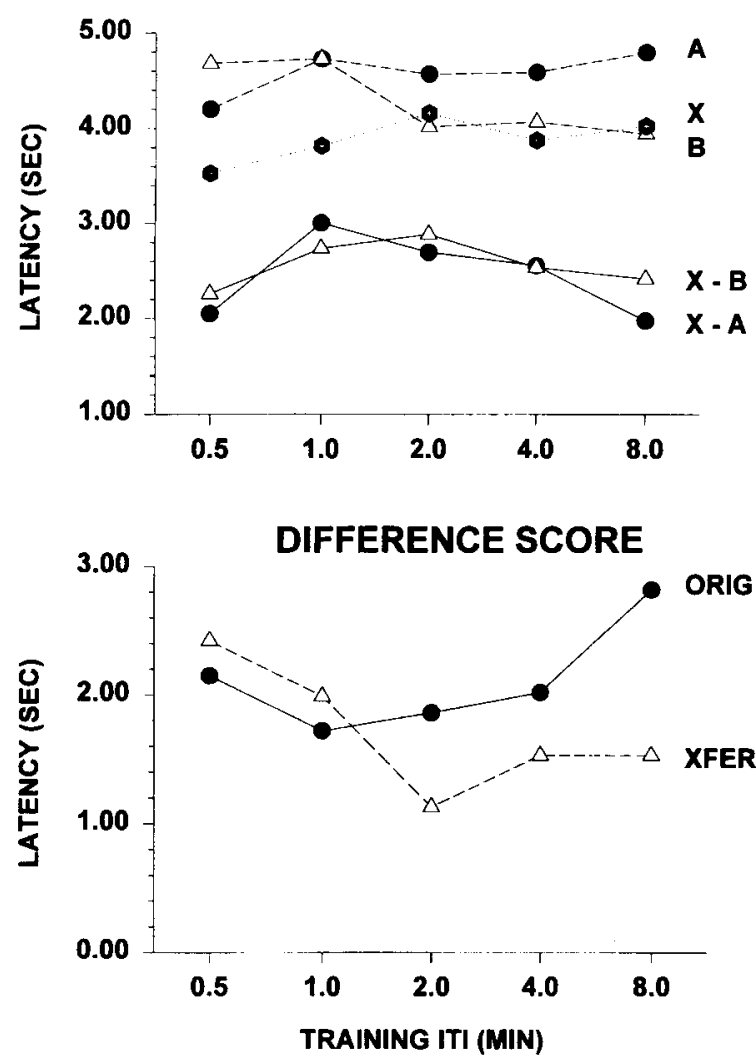

Figure 10. Performance during the first transfer test of Experiment 1 , in which the intertrial intervals (ITIs) were the mean of the original training intervals. The groups, indicated by their training ITIs, are arrayed along the abscissa. The top panel shows the mean latencies to the first response to the original (A) and transfer (B) targets presented alone or when preceded by the $X$ feature and to the first response during the interval that normally contained the target on feature-alone $(X)$ trials. The bottom panel shows, for both the original, $X \rightarrow A+/ A-$ (ORIG), and transfer, $X \rightarrow B+/ B-(X F E R)$, discriminations, the mean difference between the latency to the first response to a target when it was presented alone and when it was preceded by the feature $(X)$.

$(\mathrm{X} \rightarrow \mathrm{A}+$ vs. $\mathrm{A}-)$ discrimination did not differ across the groups $(F<1)$. However, responding on the original $\mathrm{X} \rightarrow \mathrm{A}$ compound trials had shorter latencies in the groups with intermediate ITIs, as indicated by a reliable quadratic trend across groups $[F(1,35)=10.02]$ but no reliable linear trend $(F<1)$; Newman-Keuls comparisons showed a reliable difference in $\mathrm{X} \rightarrow \mathrm{A}$ response latencies between Groups $0.5-10$ and 1-10 only. Response latencies on A-alone trials did not differ across the groups $(F<1)$.

Also as in Experiment 1, there was more transfer the shorter the ITI, as indicated by a significant linear trend across groups in the transfer discrimination difference scores $[F(1,35)=4.82]$ and no reliable quadratic or higher order trends. However, the origin of these greater difference scores in short-ITI groups were higher latencies on B-alone trials rather than lower latencies on $\mathrm{X} \rightarrow \mathrm{B}$ trials as found in Experiment 1. The linear trend across groups in response latencies on B-alone trials was reliable $[F(1,35)=7.74]$ and no higher order trends were significant. Response latencies on $\mathrm{X} \rightarrow \mathrm{B}$ trials did not differ across the groups $(F<1)$. Despite this different origin of differences in transfer performance, in Experiment 2 as in Experiment 1, the shorter the ITI, the greater the difference between the original and transfer discrimination difference scores. Those differential difference scores differed reliably across the groups $[F(4,35)=$ $3.13]$ with a reliable linear trend across groups $[F(1,35)=$ 8.17]; no higher order trend was reliable. Finally, the latencies to respond on $\mathrm{X}$-alone trials did not differ among the groups $(F<1)$.

Figure 11 shows performance during Test 2, in which trials were presented with 1-min ITIs in all groups. As in Experiment 1, performance on the original discrimination was disrupted in the groups that were trained with

\section{TEST 2: 1-MIN ITIS}
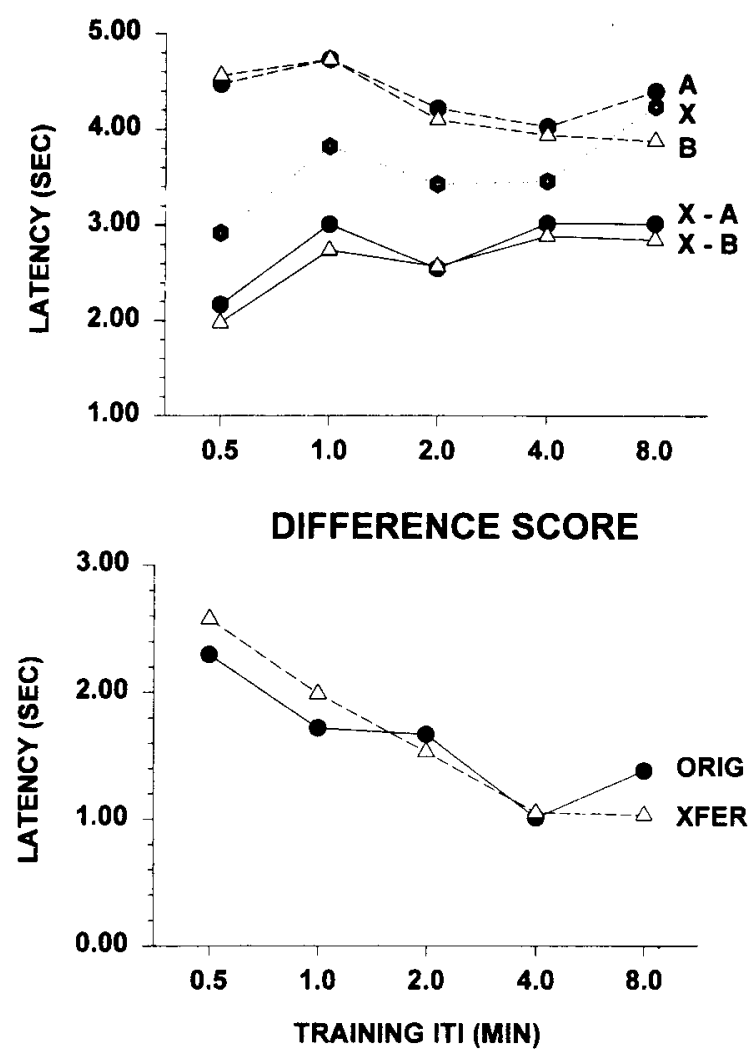

Figure 11. Performance during the transfer test of Experiment 2 in which the intertrial intervals (ITIs) were $1 \mathrm{~min}$ in all goups. The groups, indicated by their training ITIs, are arrayed along the abscissa. The top panel shows the mean latencies to the first response to the original (A) and transfer (B) targets presented alone or when preceded by the $X$ feature and to the first response during the interval that normally contained the target on feature-alone $(X)$ trials. The bottom panel shows, for both the original, $X \rightarrow A+/ A-$ (ORIG), and transfer, $X \rightarrow B+/ B-$ (XFER), discriminations, the mean differences between the latencies to the first response to a target when it was presented alone and when it was preceded by the feature $(X)$. 
longer ITIs. Latencies of responding on the original $\mathrm{X} \rightarrow \mathrm{A}$ compound were longer with longer ITIs $[F(1,35)=4.23]$, and latencies to respond on B-alone trials were shorter, the longer the ITI $[F(1,35)=5.07]$. The discrimination difference scores for both the original $[F(1,35)=4.36]$ and the transfer $[F(1,35)=9.69]$ discriminations were smaller, the longer the ITI; there were no reliable differences between the difference scores for the original and transfer discriminations across the groups $(F<1)$. Finally, response latencies on feature-alone trials did not differ among the groups $[F(4,35)=1.44]$.

Figure 12 shows performance during Test 3 , in which trials were presented with 8-min ITIs in all groups. As in Experiment 1, performance was roughly similar to that observed in Test 1, but with a suggestion of poorer performance in the groups trained with the shorter ITIs. Re-
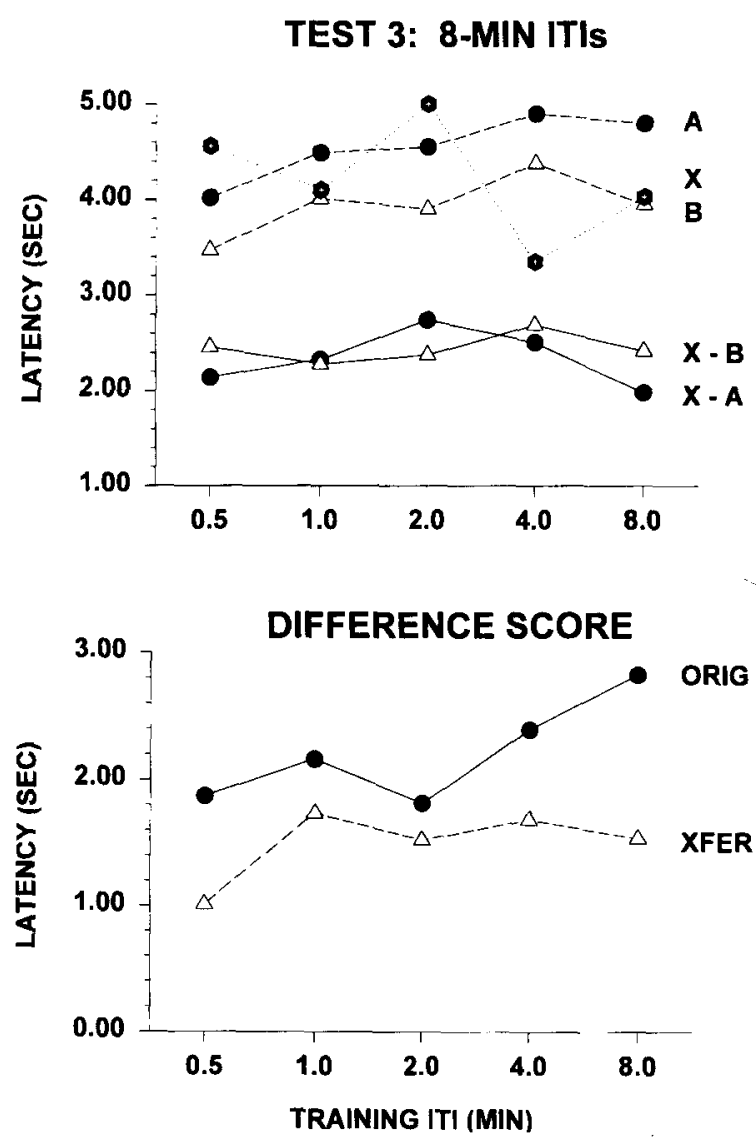

Figure 12. Performance during the transfer test of Experiment 2, in which the intertrial intervals (ITIs) were $8 \mathrm{~min}$ in all groups. The groups, indicated by their training ITIs, are arrayed along the abscissa. The top panel shows the mean latencies to the first response to the original (A) and transfer (B) tangets presented alone or when preceded by the $X$ feature and to the first response during the interval that normally contained the target on feature-alone $(X)$ trials. The bottom panel shows, for both the original, $X \rightarrow A+/ A-$ (ORIG), and transfer, $\mathbf{X} \rightarrow \mathbf{B}+/ \mathbf{B}-$ (XFER), discriminations, the mean differences between the latencies to the first response to a target when it was presented alone and when it was preceded by the feature $(X)$. sponse latencies on $\mathrm{X} \rightarrow \mathrm{A}$ and $\mathrm{X} \rightarrow \mathrm{B}$ compound trials did not differ across groups $\left(F_{S}<1\right)$, but the latencies to respond on both $\mathrm{A}-$ and $\mathrm{B}$-alone trials were greater, the longer the training ITI $[F \mathrm{~s}(1,35) \geq 6.07]$. Furthermore, although neither the $\mathrm{A}$ minus $\mathrm{X} \rightarrow \mathrm{A}$ original discrimination difference scores nor the $\mathrm{B}$ minus $\mathrm{X} \rightarrow \mathrm{B}$ transfer discrimination difference scores showed reliable differences across groups $[F \mathrm{~s}(4,35) \leq 1.57]$, both the differences between those difference scores $[F(1,35)=3.87]$ and the difference between response latencies on $\mathrm{X} \rightarrow \mathrm{A}$ and $\mathrm{X} \rightarrow \mathrm{B}$ trials showed reliable quadratic trends across groups $[F s(1,35)=4.66$ and 5.27 , respectively]. These trends may reflect the combination of generalization decrement between training and testing conditions in the groups trained with shorter ITIs and the initially greater transfer observed in those groups when tested with the original training ITIs (Test 1 ).

Postextinction transfer test. Because feature extinction typically reduces simple feature conditioning substantially, but leaves occasion setting intact, Test 4 was intended as a test of occasion setting under conditions of reduced feature conditioning. Relative to Test 1 , the latency to respond during the test interval on featurealone trials increased in all rats (except those that did not respond in Test 1); the latency to respond in this interval did not differ from that during pre-CS intervals. Thus, the extinction procedure evidently reduced feature conditioning.

Figure 13 shows performance in Test 4 . First, despite extinction of the $X$ feature prior to Test 4 , some performance of the original discrimination was maintained in most subjects; individual contrasts of response latencies on $\mathrm{X} \rightarrow \mathrm{A}$ and $\mathrm{A}$-alone trials were reliable in all groups $[F \mathrm{~s}(1,140) \geq 3.95]$ except Group 0.5-10. Second, responding during the original $\mathrm{X} \rightarrow \mathrm{A}$ compound occurred with shorter latencies, the longer the ITI $[F(1,35)=$ 17.35], indicating that $X$ feature extinction especially increased response latencies when short ITIs had been used in training. Third, there were no effects of group or trends across groups for response latencies during any other cue $(p s \geq .10)$. Fourth, transfer responding was not maintained; individual contrasts of response latencies on $\mathrm{X} \rightarrow \mathrm{B}$ and $\mathrm{B}$-alone trials failed to reach significance in any of the groups $[F \mathrm{~s}(1,140) \leq 3.66]$. Consequently, performance on the original discrimination was better, the longer the ITI $[F(1,35)=14.80]$, whereas there was no such trend for performance on the transfer discrimination $[F(1,35)<1]$. Although the difference between those difference scores also appeared to increase as a function of ITI, that trend was not reliable $[F(1,35)=$ $2.95, p=.095]$.

The top half of Figure 14 shows the difference between Test 4 (postextinction) and Test 1 (preextinction) in the latencies to respond to the original (A) and transfer (B) targets on compound trials. Although, because of the lack of any no-extinction control conditions, these differences cannot be solely attributed to the effects of the intervening extinction procedures, examination of 


\section{POST-EXTINCTION TEST}
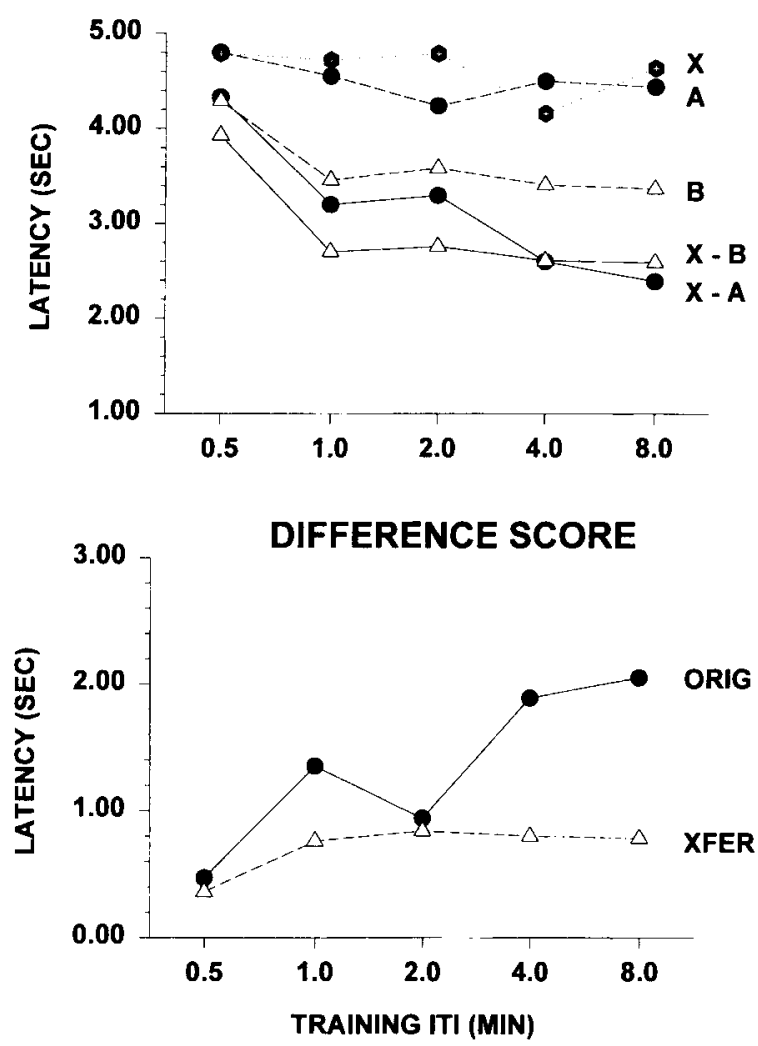

Figure 13. Performance during the fourth transfer test of Experiment 1 , which was identical to Transfer Test 1 but which occurred after repeated nonreinforced presentations of the $X$ feature in all groups. The groups, indicated by their training ITIs, are arrayed along the abscissa. The top panel shows the mean latencies to the first response to the original $(A)$ and transfer $(B)$ targets presented alone or when preceded by the $X$ feature and to the first response during the interval that normally contained the target on feature-alone $(X)$ trials. The bottom panel shows, for both the original, $\mathbf{X} \rightarrow \mathbf{A}+/ \mathbf{A}-$ (ORIG), and transfer, $X \rightarrow B+/ B-(X F E R)$, discriminations, the mean differences between the latencies to the first response to a target when it was presented alone and when it was preceded by the feature (X).

between-group differences in the amount of change in performance between these two identical tests was illuminating nonetheless. Latencies to respond on both $\mathrm{X} \rightarrow \mathrm{A}$ and $\mathrm{X} \rightarrow \mathrm{B}$ trials were affected only by the intervening treatment in the group trained with the shortest ITI (Group 0.5-10). Newman-Keuls comparisons of the Test 4 minus Test 1 difference scores showed greater differences in Group 0.5-10 than in any of the other groups.

However, it is important to note that analyses of response rates in these two test sessions led to a different conclusion about the effects of feature extinction on compound responding. The bottom half of Figure 14 shows the response-rate difference between Test 4 and Test 1 . Response rates during the target cues in the original and transfer compounds showed large decreases from Test 1 levels of responding, suggesting that simple conditioning contributed substantially to the perfor- mance of all groups, not just Group 0.5-10. However, as with the latency measure, those differences were greatest in Group 0.5-10 (Newman-Keuls contrasts). Thus, with both measures, it is appropriate to infer a greater contribution of simple conditioning to compound responding in Group 0.5-10 than in the other groups. I have no explanation for why latency and rate measures diverged in Test 4 of Experiment 2, but not in other tests.

\section{Discussion}

On the whole, the effects of ITI on discrimination performance in Experiment 2 were similar to those seen in Experiment 1. The longer the ITI in training, the more rapid the acquisition of the discrimination, the less transfer of the feature's power to a trained and extinguished target stimulus, and the less effect of nonreinforced feature presentations on discrimination performance. These results are consistent with the possibility that the shorter ITIs encouraged proportionally less occasion setting and more conditioning to the feature. However, that claim is again complicated by the lack of a reliable difference in responding controlled directly by the feature as a function of ITI. The performance of Group 0.5-10 further muddles this description. On the one hand, simple con-
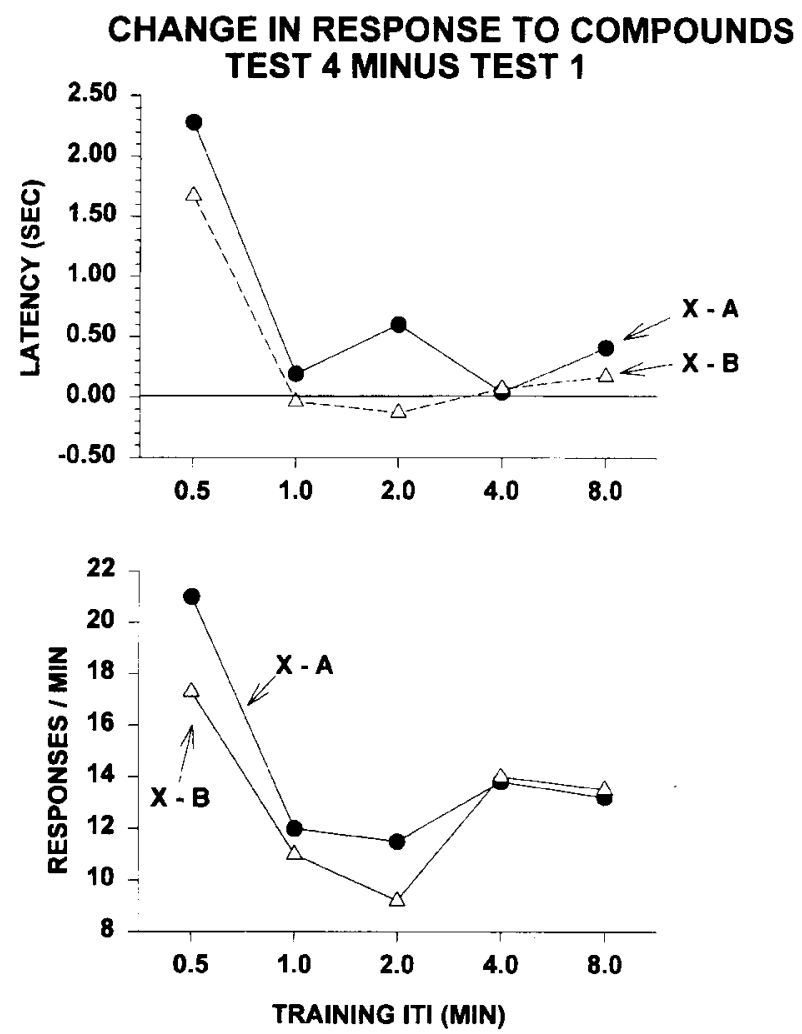

Figure 14. The differences between responding on the original $(X \rightarrow A)$ or transfer $(X \rightarrow B)$ compounds in Transfer Test 1 and Transfer Test 4 (after extinction of the feature cue, $X$ ), in Experiment 2. The groups, indicated by their training intertrial intervals (ITIs), are arrayed along the abseissa. The top panel shows the mean differences in response latency; the bottom panel shows the mean differences in response rates. 
ditioning proceeded more slowly in that group than in any of the other groups, both in initial acquisition and in discrimination training. But the results of the transfer tests and postextinction test sessions suggested that once high levels of discrimination performance were reached in that group, that performance reflected more simple conditioning (and less occasion setting) than was seen in the longer ITI groups.

Also as in Experiment 1, the effects of ITI were not attributable solely to performance factors, but involved effects on learning as well: differences among the groups were maintained when they were tested with common ITIs. However, there were significant local performance effects: both lengthening and shortening the test ITI tended to disrupt discrimination performance.

\section{GENERAL DISCUSSION}

Two experiments showed consistent effects of ITI on the rate of acquisition of serial FP discrimination performance, transfer to separately trained target cues, and the immunity of discrimination performance to feature extinction. The two experiments used different FTIs, chosen so that the ITI/FTI ratios were identical across experiments. Otherwise, the procedures of the experiments were identical, except for the number of training sessions used (which differed so that subjects in all of the groups in both experiments would enter the test sessions with similar levels of responding to the original serial compound cues). Consequently, statistical comparisons of the data from the two studies seemed appropriate. Two-way ANOVAs with ITI/FTI ratio as one (withinexperiment) factor and FTI as the other (betweenexperiment) factor were performed, as were ANOVAs with FTI and ITI as factors, which compared only the performances of the groups that received training with the same ITIs (rather than the same ITI/FTI ratios). These analyses were applied to five data sets from the two experiments: performance in the initial nondiscriminative conditioning phase, acquisition of discriminative responding, amount of transfer, amount of extinctioninduced loss of discrimination performance, and discrimination performance maintained after feature extinction.

\section{Nondiscriminative Conditioning}

Performance in this phase (Figures 1 and 8 ) was superior in rats trained with the short FTI, but, unlike data from other conditioning preparations, ITI/FTI ratio or ITI had no systematic effect. Both ITI/FTI $\times$ FTI and ITI $\times$ FTI ANOVAs on latencies averaged over the entire phase showed a reliable effect only of FTI $[F(1,70)=$ 3.80 and $F(1,56)=5.67$, respectively].

This lack of systematic between-trial interval effects was maintained in later phases of the experiments as well. Responding during the reinforced serial compounds did not differ as a function of ITI during the FP discrimination phases, nor was either conditioning or extinction of the separately trained B cue affected by those intervals. In the Discussion section of Experiment 1, I noted several possible accounts for why these experiments failed to reveal ITI or ITI/FTI effects on simple nondiscriminative conditioning. Although they remain plausible, another possibility worth considering is that, within the range of ISIs and ITIs examined here, simple conditioning in this operant conditioning preparation is not affected by those factors. It should be recognized that demonstrations of invariance of conditioning with constant ITI/FTI ratios have almost exclusively used the pigeon autoshaping preparation.

\section{Discriminative Conditioning}

As anticipated from previous data from serial FP discriminations (Holland, 1986a, 1991, 1995), acquisition of the serial FP discrimination improved both as the within-trial interval (FTI) decreased and as the betweentrial interval (ITI), or ITI/FTI ratio, increased. Figure 15 plots (on a log-log scale, with the ordinate scale inverted so that a rising curve indicates increasingly rapid acquisition) the number of trials to reach a discrimination criterion $(1.00-\mathrm{sec}$ difference in response latency between $\mathrm{S}-$ and $\mathrm{S}+$ trials) as a function of the ratio of ITI to FTI, in both experiments. Unlike in the simple conditioning data of Gibbon et al. (1977) and the DMTS performance data of Roberts and Kraemer (1982, Experiments 1 and 2 ), the trials-to-discrimination criterion was not constant for equal ratios of the between- and within-trial intervals. Rather, performance with the 10-sec FTI was superior to that with the 20 -sec FTI at most ITI/FTI ratios (abscissa in Figure 15) and at the shorter ITI values (labels in Figure 15). This description was supported statistically: An ITI/FTI $\times$ FTI ANOVA showed a reliable

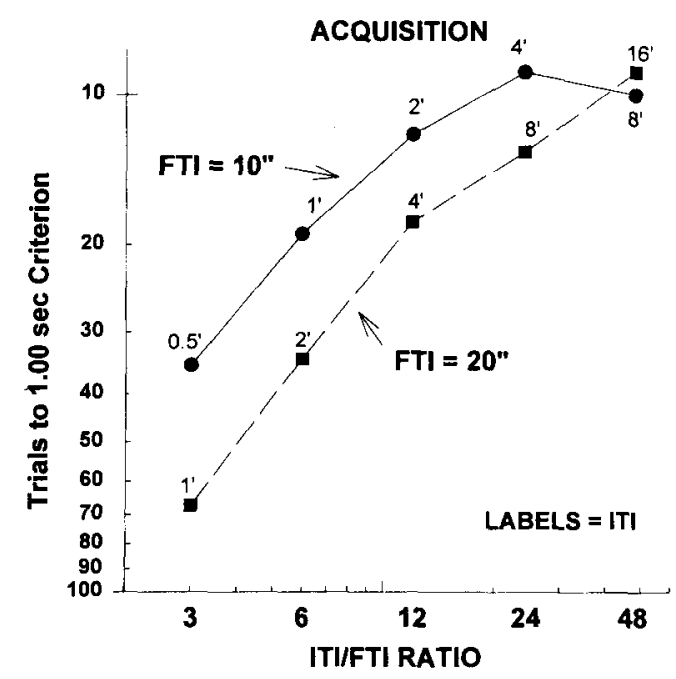

Figure 15. Mean number of reinforced compound trials (on a log scale) before reaching a criterion of two successive sessions with a difference between the latency of responding to the target cue on nonreinforced and reinforced trials greater than $1.0 \mathrm{sec}$, in Experiments 1 and 2. The abscissa shows the ratio of the intertrial interval (ITI) to the feature-target interval (FTI), on a log scale, of the various groups; the parameter distinguishes rats trained with the 10-sec (Experiment 2) and 20-sec (Experiment 1) FTIs; and the point labels indicate the mean ITI used in the groups represented by each point. 
effect of both ITI/FTI ratio $[F(4,70)=9.56]$ and FTI $[F(1,70)=12.73]$ with no interaction $(F<1.56)$, and individual between-groups Tukey contrasts were reliable for each ratio except 48 . An ITI $\times$ FTI analysis showed reliable effects of ITI $[F(3,56)=6.14]$ and FTI $[F(1,56)=$ $5.83]$, as well as a reliable ITI $\times$ FTI interaction $[F(3,56)=5.02]$. Thus, despite the lack of invariance with equal ratios, the ITI/FTI ratio is nevertheless a useful metric in this situation: the effects of ITI/FTI ratio and FTI were additive, unlike those of ITI alone and FTI. It is perhaps worth noting, in regard to the lack of ratio invariance observed here, that Roberts and Kraemer (1982) found the constancy of performance at equal ITI/delayinterval ratios to hold only with delay intervals much shorter than those investigated here, and when the ITI was constant, rather than variable, as in the present study.

These acquisition data do not distinguish between solutions based on the acquisition of simple conditioning or of occasion setting. Nevertheless, it is worth recalling that in the previous nondiscriminative conditioning phase, simple conditioning was not reliably affected by ITI/FTI ratio or ITI. That finding suggests that the FTI/ ITI effects seen in the acquisition of the discrimination may primarily involve occasion setting. Consideration of interval effects on the remaining measures will address this issue.

\section{Transfer}

Transfer of the feature's powers to a separately trained and extinguished cue was greater the shorter the ITI. Figure 16 plots the difference between latencies of responding to the original target CS and of responding to the trained and extinguished transfer target in both experiments, with the ordinate scale inverted so that the falling curve reflects decreasing amounts of transfer. Transfer was consistently greater at short ITIs or smaller ITI/FTI ratios. Although at most values of the ITI/FTI ratio, transfer was also greater with the shorter $(10-\mathrm{sec})$ FTI, the transfer performance of rats trained with 10 and 20 -sec FTIs did not differ when groups trained with equal ITIs were compared. An ITI/FTI $\times$ FTI ANOVA showed reliable effects of both ITI/FTI ratio $[F(4,70)=$ $4.83]$ and $\mathrm{FTI}[F(1,70)=7.97]$ and no interaction $(F<1)$, and an ITI $\times$ FTI analysis showed a reliable effect of ITI $[F(3,56)=4.57]$ but no significant effect of FTI $[F(1,56)=1.84]$ or ITI $\times$ FTI interaction $(F<1)$.

Elsewhere, I have interpreted transfer to separately trained cues as an indication of simple conditioning, rather than occasion setting. To the extent that the feature controlled responding directly, that responding would sum with responding controlled by other target cues (i.e., transfer would be observed). In that context, Figure 16 could be interpreted as indicating that simple conditioning of the feature was greater with shorter FTIs (as is typically observed) and with smaller ITI/FTI ratios or shorter ITIs (in contrast to most existing data). Because initial performance on the original discriminations was superior with longer ITIs or ITI/FTI ratios, these transfer data imply that use of occasion setting was especially en-

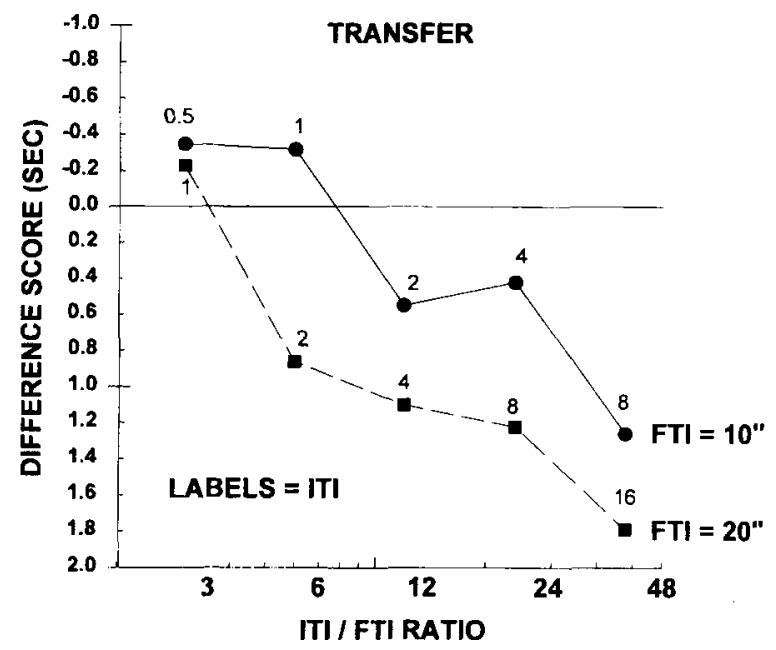

Figure 16. Mean difference in latency between discrimination difference scores for the original and transfer discriminations in Experiments 1 and 2 . The abscissa shows the ratio of the intertrial interval (ITI) to the feature-target interval (FTI), on a log scale, of the various groups; the parameter distinguishes rats trained with the 10 $\sec$ (Experiment 2) and 20-sec (Experiment 1) FTIs; and the point labels indicate the mean ITI used in the groups represented by each point. The larger the difference score, the poorer the transfer.

hanced with longer ITIs or ITI/ISI ratios. The depressive effects of longer ITIs or ITI/FTI ratios on simple conditioning might be reconciled with more typical facilitatory outcomes if those parameters exerted their influence primarily on occasion setting, and occasion-setting and simple conditioning strategies competed (Holland, 1983).

But, as briefly noted in the Discussion section of Experiment 1 , transfer may not unequivocally measure simple conditioning. Although Holland ( 1986b, 1989) found little evidence for transfer of Pavlovian occasion setting to trained and extinguished cues, Holland (1991) found moderate levels of transfer to such cues in operant procedures under some circumstances. So, the observation of transfer to the trained and extinguished cues in the present experiments does not unequivocally indicate simple conditioning, and thus temporal variables may instead affect transfer effects within occasion setting in other ways (e.g., Holland, 1986a). Longer ITIs may enhance the breadth of a feature's occasion-setting powers or the ability of a separately trained and extinguished cue to serve as a target of transfer. For example, the use of shorter ITIs may enhance confusion or generalization between the various target cues in short-term memory, encouraging transfer outcomes. Or some temporal parameters may selectively encourage configural processes, whereby a unit comprising feature and target is associated with the US at the expense of both occasion setting and simple conditioning.

\section{Extinction-Induced Loss of Responding to Original Compound}

Nonreinforced feature-alone presentation (or some other unspecified consequence of the procedures that 
separated Tests 1 and 4) had larger detrimental effects on responding to the training compound when the FTIs, ITI/FTI ratios, and/or ITIs were shorter. Figure 17 plots the change in response rate between Tests 1 and 4 in both experiments. Responding to the original compound stimulus was more affected after training with the shorter FTI and with smaller ITI/FTI ratios or shorter ITIs. The effects of ITI and ITI/FTI ratio were especially obvious with the longer FTIs, and the effects of FTI were greater with larger ITI/FTI ratios and longer ITIs. An ITI/FTI $\times$ FTI ANOVA showed reliable effects of both ITI/FTI ratio $[F(4,70)=3.61]$ and $\mathrm{FTI}[F(1,70)=15.60]$, with a reliable interaction $[F(3,70)=8.63]$ as well, and an ITI $\times$ FTI analysis showed a reliable effect of ITI $[F(3,56)=2.99]$ and FTI $[F(1,56)=11.18]$ and a significant ITI $\times$ FTI interaction $[F(3,56)=3.02]$.

Elsewhere, I have interpreted such losses as reflecting the loss of simple conditioning to the feature. To the extent that the feature controlled responding directly, that responding would be diminished as a consequence of nonreinforced feature presentations (extinction). Given that assumption, the data shown in Figure 17, like those of the transfer tests, suggest that simple conditioning within serial FP discriminations was greater with shorter FTIs (as is typically observed) and with smaller ITI/FTI ratios or shorter ITIs, perhaps as a consequence of reduced occasion setting (which may be mutually competitive with simple conditioning) at those intervals.

\section{Postextinction Responding}

Finally, residual responding to the original training compounds after feature extinction was greater, the

\section{LOSS OF RESPONDING TO ORIGINAL COMPOUND}

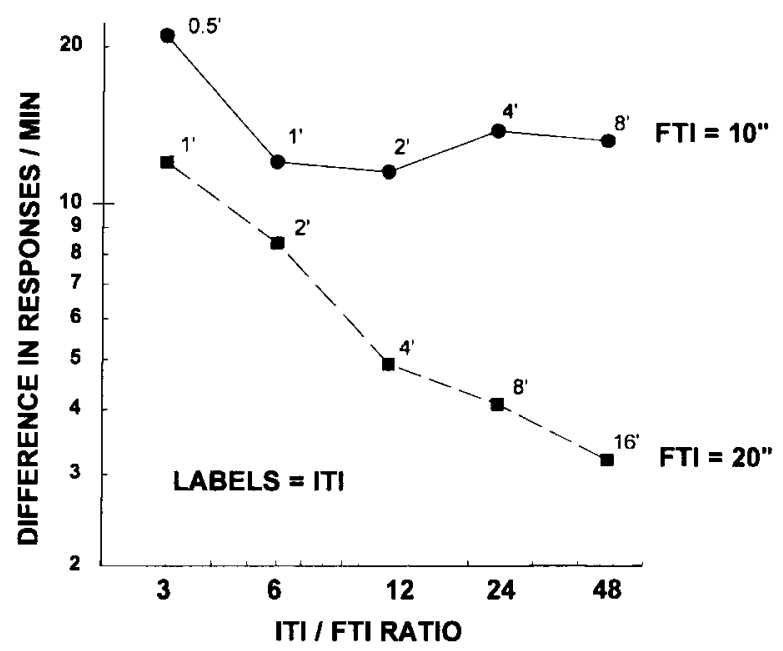

Figure 17. Mean difference in response rate (on a log scale) between Test 4 and Test 1 in the original discrimination difference scores in Experiments 1 and 2. The abscissa shows the ratio of the intertrial interval (ITI) to the feature-target interval (FTI), on a log scale, of the various groups; the parameter distinguishes rats trained with the 10-sec (Experiment 2) and 20-sec (Experiment 1) FTIs; and the point labels indicate the mean ITI used in the groups represented by each point. The larger the difference score, the more responding was affected by extinction of the feature, $X$.

\section{POST-EXTINCTION ORIGINAL DISCRIMINATION}

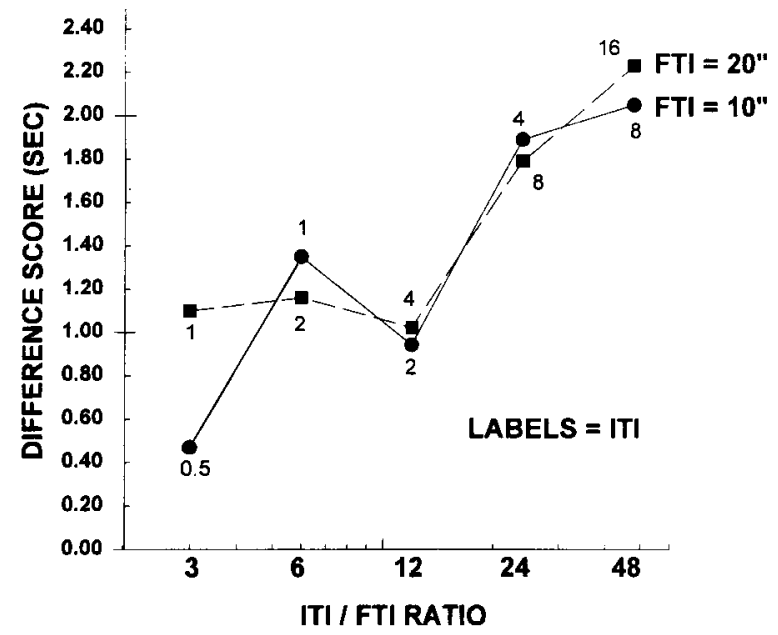

Figure 18. Mean discrimination difference scores for the original discriminations during the postextinction Test 4 in Experiments 1 and 2, a measure thought to show occasion setting with relatively little contribution of simple conditioning. The abscissa shows the ratio of the intertrial interval (ITI) to the feature-target interval (FTI), on a log scale, of the various groups; the parameter distinguishes rats trained with the 10-sec (Experiment 2) and 20-sec (Experiment 1) FTIs; and the point labels indicate the mean ITI used in the groups represented by each point.

larger the ITI/FTI ratio or the longer the ITI. Figure 18 plots the difference scores for responding to the original training target in Test 4 in the two experiments. An ITI/FTI $\times$ FTI ANOVA showed a reliable effect only of ITI/FTI $[F(4,70)=3.93]$, and an ITI $\times$ FTI analysis showed an effect only of ITI $[F(3,56)=2.77]$. If this residual responding measures occasion setting relatively free of simple conditioning effects, these data indicate most directly that longer ITIs (or greater ITI/FTI ratios) enhance the acquisition of occasion setting.

Note, however, that these data may underestimate the effect of those intervals on occasion setting in Experiment 1 (10-sec FTIs), because the rats that were trained with the shorter ITIs received more discrimination training in an attempt to equate discrimination performance at the time of the initial transfer tests. Equally extended training with the longer ITIs might have generated even more residual performance, although it is likely that training was asymptotic in all cases. Likewise, evaluation of the effects on residual responding of FTI or of the FTI $\times$ ITI interaction is problematic, although the lack of a difference between the 10- and 20-sec FTIs is consistent with previous data (Holland, 1992; Ross \& Holland, 1981). Notice, however, that this same criticism is not applicable to the data portrayed in Figure 15 (which shows the number of trials needed to reach a constant criterion) and much less applicable to those shown in Figures 16 and 17, in which the use of difference measures should reduce the impact of this confounding factor. 
Previously, Holland (1992) distinguished between occasion setting and simple conditioning functions of feature cues in FP discriminations in terms of differential effects of transfer and extinction. By those criteria, all of the present results indicate that occasion setting is enhanced by the use of longer ITIs in serial FP discriminations. More problematic is the inference, from those same criteria, that simple conditioning of the feature in serial FP discriminations is diminished by the use of longer intervals. First, this inference is at odds with the responding observed on feature-alone test trials. In Experiment 1 , the differential patterns of transfer and extinction effects across ITI were observed despite no evidence for any direct control of responding by the feature, and responding on feature-alone trials was not reliably affected by the ITI in either experiment. Although response timing (see the Discussion section of Experiment 1) may have been a factor, this conclusion also contradicts the frequent observation that longer ITIs enhance conditioning. One way out of this dilemma is to assume first that (at least within the range of intervals studied here) between-trial temporal variables affect occasion setting directly and more dramatically than they do simple conditioning, and second that the establishment of occasion setting interferes with simple conditioning, perhaps including the reduction of previously established responding.

On the other hand, Holland's (1992) distinctions between simple conditioning and occasion setting may be somewhat simplistic. As noted earlier, the differential transfer and extinction effects found here may not be solely attributable to different amounts of simple conditioning to the feature cues. In this context, note that although the implications of the transfer and extinction data were roughly comparable, they were not identical. Specifically, FTl exerted a much greater influence on the effectiveness of extinction than it did on the amount of transfer.

Regardless of the interpretation of the transfer and extinction data, the effects of ITI on the acquisition and performance of the FP discrimination are consistent with the simple gestalt view described in the introduction. The use of longer ITIs might facilitate grouping the feature with the [target-US] unit rather than with preceding events, such as target-alone or US presentations, while the integrity of the [target-US] unit is maintained by nonzero FTIs.

Unfortunately, these experiments neither reveal a mechanism for interval effects nor identify which of several intertrial temporal relations-such as the interval between any two trials, the interval between deliveries of the food USs, the interval between reinforced serial compound trials, the interval between nonreinforced targetalone trials, the interval between trials of different types, and so forth-contribute to the effects observed. Any or all of these intervals may influence the rate and nature of learning of FP discriminations. For example, many studies (e.g., Mustaca, Gabelli, Papini, \& Balsam, 1991) have indicated that higher rates of US presentation (as occurred in our shorter ITI conditions) encourage greater context conditioning, which might in turn influence the effectiveness of various trial types in generating discrimination learning. In contrast, Tiffany, Maude-Griffin, and Dorbes (1991) found that the superiority of long ITIs for generating greater morphine tolerance effects (attributed to conditioning) was unaffected by unsignaled, interpolated US presentations, suggesting that the interval between conditioning trials, rather than USs, was critical.

Finally, in an unpublished experiment that used an "ambiguous feature" discrimination procedure $(\mathrm{X} \rightarrow \mathrm{A}+1$ $\mathrm{A}-/ \mathrm{X} \rightarrow \mathrm{B}-/ \mathrm{B}+)$ related to the $\mathrm{FP}$ discriminations used here, Holland and Gallagher (1994) noted an interaction between ITI and trial sequence that was consistent with the suggestion made by Kehoe, Cool, and Gormezano (1991) that longer ITIs enhance discrimination learning by reducing proactive interference from preceding trials. With short (1-min) ITIs, they found substantial decrements in discrimination performance when target-alone trials were preceded by feature $\rightarrow$ target trials as opposed to when they were preceded by target-alone trials. In contrast, with long (8-min) ITIs, trial sequence was irrelevant. Clarification of the contribution of ISI and ITI to FP discrimination performance awaits further study.

\section{REFERENCES}

Gibbon, J., Baldock, M. D., Locurto, C. M., Gold, L., \& Terrace, H. S. (1977). Trial and intertrial durations in autoshaping. Journal of Experimental Psychology: Animal Behavior Processes, 3, 264284.

Gormezano, I., \& MoOre, J. W. (1969). Classical conditioning. In M. H. Marx (Ed.), Learning: Processes (pp. 121-203). London: Macmillan.

Grant, D. S. (1975). Proactive interference in pigeon short-term memory. Journal of Experimental Psychology: Animal Behavior Processes, 1, 207-220.

Holland, G. A. (1953). Simple trial-and-error learning: Massed and distributed trials with habits of unequal initial strength. Journal of Comparative \& Physiological Psychology, 46, 90-94

Holland, P. C. (1983). Occasion-setting in Pavlovian feature positive discriminations. In M. L. Commons, R. J. Herrnstein, \& A. R. Wagner (Eds.), Quantitative analyses of behavior: Discrimination processes (Vol. 4, pp. 183-206). New York: Ballinger.

Holland, P. C. (1986a). Temporal determinants of occasion setting in feature-positive discriminations. Animal Learning \& Behavior, 14, $111-120$

Holland, P. C. (1986b). Transfer after serial feature positive discrimination training. Learning \& Motivation, 17, 243-268.

Holland, P. C. (1989). Feature extinction enhances transfer of occasion setting. Animal Learning \& Behavior, 17, 269-279.

Holland, P. C. (1991). Acquisition and transfer of occasion setting in operant feature positive and feature negative discriminations. Learning \& Motivation, 22, 366-387.

Holland, P. C. (1992). Occasion setting in Pavlovian conditioning. In D. Medin (Ed.), The psychology of learning and motivation (Vol. 28, pp. 69-125). San Diego, CA: Academic Press.

Holland, P. C. (1995). Transfer of occasion setting across stimulus and response in operant feature positive discriminations. Learning \& Motivation, 26, 239-263.

Holland, P. C., \& Gallagher, M. (1994). [Intertrial interval determines the effects of hippocampal lesions on conditional discrimination performance]. Unpublished raw data.

Holland, P. C., \& HAAS, M. L. (1993). The effects of target salience 
in operant feature positive discriminations. Learning \& Motivation, 24, 119-140.

Kehoe, E. J., Cool, V., \& Gormezano, I. (1991). Trace conditioning of the rabbit's nictitating membrane response as a function of CS-US interstimulus interval and trials per session. Learning \& Motivation, 22, 269-290.

Mustaca, A. E., Gabelli, F., Papini, M. R., \& Balsam, P. (1991). The effects of varying the interreinforcement interval on appetitive contextual conditioning. Animal Learning \& Behavior, 19, 125-139.

PeArCE, J. M. (1987). A model for stimulus generalization in Pavlovian conditioning. Psychological Review, 94, 61-73.

ResCoRla, R. A. (1985). Conditioned inhibition and facilitation. In R. R. Miller \& N. E. Spear (Eds.), Information processing in animals: Conditioned inhibition (pp. 299-326). Hillsdale, NJ: Erlbaum.

Roberts, W. A., \& Kraemer, P. J. (1982). Some observations of the effects of intertrial interval and delay on delayed matching to sample in pigeons. Journal of Experimental Psychology: Animal Behavior Processes, 8, 342-353.

Ross, R. T., \& Holland, P. C. (1981). Conditioning of simultaneous and serial feature-positive discriminations. Animal Learning \& Behavior, 9, 293-303.

SPENCE, K. W., \& Norris, E. B. (1950). Eyelid conditioning as a function of the inter-trial interval. Journal of Experimental Psychology, 40, 716-720.

Tiffany, S. T., Maude-Griffin, P. M., \& Drobes, D. J. (1991). Effect of interdose interval on the development of associative tolerance to morphine in the rat: A dose-response analysis. Behavioral Neuroscience, 105, 49-61.

(Manuscript received August 2, 1994; revision accepted publication December 12, 1994.) 